Check for updates

Cite this: Mater. Adv., 2022, 3,2200

Received 8th October 2021 Accepted 19th January 2022

DOI: 10.1039/d1ma00934f

rsc.li/materials-advances

\title{
Facet-dependent carrier dynamics of cuprous oxide regulating the photocatalytic hydrogen generation $\dagger$
}

\author{
Cui Ying Toe, (D) ${ }^{a}$ Marlene Lamers, ${ }^{b}$ Thomas Dittrich, ${ }^{c}$ Hassan A. Tahini, ${ }^{d}$ \\ Sean C. Smith, ' Jason Scott, (iD a Rose Amal, (iD a Roel van de Krol, (iD b \\ Fatwa F. Abdi iD *b and Yun Hau Ng iD *ae
}

\begin{abstract}
The intrinsic carrier dynamics of cuprous oxide $\left(\mathrm{Cu}_{2} \mathrm{O}\right)$ are known to have a crucial influence on photocatalytic performances. The photoactivity of rhombic dodecahedral $\mathrm{Cu}_{2} \mathrm{O}$ with dominant $\{110\}$ facets $\left(\mathrm{RD}-\mathrm{Cu}_{2} \mathrm{O}\right)$ is demonstrated to surpass that of cubic $\mathrm{Cu}_{2} \mathrm{O}$ with $\{100\}$ surfaces $\left(\mathrm{CB}-\mathrm{Cu}_{2} \mathrm{O}\right)$. Time resolved microwave conductivity (TRMC) measurements reveal the higher carrier mobility of $\mathrm{RD}-\mathrm{Cu}_{2} \mathrm{O}$ when compared to $\mathrm{CB}-\mathrm{Cu}_{2} \mathrm{O}$. Additionally, modulated surface photovoltage (SPV) measurements further supported the better charge separation efficiency of $\mathrm{RD}-\mathrm{Cu}_{2} \mathrm{O}$. Although $\mathrm{CB}-\mathrm{Cu}_{2} \mathrm{O}$ exhibited more pronounce SPV signals, the homogeneous distribution of electrical fields drives the majority charge inward and led to detrimental charge recombination. In contrast, the weak SPV signals for RD- $\mathrm{Cu}_{2} \mathrm{O}$ were attributed to a modulated distribution of charges towards the facets and facet boundaries, demonstrating a better charge separation. This study shows that carrier dynamics and defect density should also be regarded as facet-dependent properties that can have deciding influence on the photocatalytic activity.
\end{abstract}

\section{Introduction}

Morphology control through crystal facet engineering has attracted significant attention due to its ability to optimize the performance of various photocatalysts. ${ }^{1}$ Given the unique facet-dependent properties, rapid advancements have been made in the synthesis of crystalline functional materials (both semiconductor and metal) with well-defined facets such as bismuth-based ternary oxides (e.g. $\mathrm{BiVO}_{4}$ and $\left.\mathrm{Bi}_{2} \mathrm{WO}_{6}\right), \mathrm{TiO}_{2}$, $\mathrm{Cu}_{2} \mathrm{O}, \mathrm{CdSe}, \mathrm{Au}$ and $\mathrm{Ag}^{2-7}$ Formation of distinctive crystal facets motivated numerous morphological studies that demonstrated enhanced reactivity and selectivity. Apart from the activity enhancement, tailoring the extent of facet exposure

\footnotetext{
${ }^{a}$ Particles and Catalysis Research Group, School of Chemical Engineering, The University of New South Wales, NSW 2052, Australia. E-mail: yunhau.ng@cityu.edu.hk

${ }^{b}$ Institute for Solar Fuels, Helmholtz-Zentrum Berlin für Materialien und Energie GmbH, Hahn-Meitner-Platz 1, Berlin 14109, Germany

${ }^{c}$ Institute for Silicon Photovoltaics, Helmholtz-Zentrum Berlin für Materialien und Energie GmbH, Kekuléstrasse 5, Berlin 12489, Germany

${ }^{d}$ Research School of Physics and Engineering, The Australian National University, Canberra, ACT 2601, Australia

${ }^{e}$ School of Energy and Environment, City University of Hong Kong, Kowloon, Hong Kong SAR, P. R. China

$\dagger$ Electronic supplementary information (ESI) available. See DOI: 10.1039/d1ma00934f
}

has also enabled the determination of specific oxidation and reduction sites on a photocatalyst. Photoreduction of $\mathrm{Pt}^{6+}$ to $\mathrm{Pt}$ and photooxidation of $\mathrm{Pb}^{2+}$ to $\mathrm{PbO}_{2}$ were first discovered to specifically occur on (110) and (011) facets of $\mathrm{TiO}_{2}$, respectively. ${ }^{8}$ Similar technique has also been employed to reveal the active photoreduction and oxidation sites of $\mathrm{BiVO}_{4},{ }^{2,9}$ BiOCl $^{10}$ and BiOBr. ${ }^{11}$ Most of the crystal facet investigations, however, focused on n-type photocatalysts and little is known about the reactivity of different facets of p-type materials.

Inspired by the above-mentioned progress in facet engineering, recent studies have shown that $\mathrm{Cu}_{2} \mathrm{O}$ with different exposed crystal planes also show facet-dependent properties manifested by its distinct photoreactivity. $\mathrm{Cu}_{2} \mathrm{O}$ has emerged as an attractive p-type semiconductor for both photocatalytic and photoelectrochemical water splitting due to its favorable electronic structure that is suitable for solar energy harvesting (i.e. bandgap of $\sim 2.0 \mathrm{eV}$ with a conduction band potential more negative than the water reduction potential). ${ }^{12}$ Architecture control of $\mathrm{Cu}_{2} \mathrm{O}$ is also one of the promising research areas owing to its ease in forming numerous morphologies such as spheres, ${ }^{13}$ plates, ${ }^{14}$ flower-like, ${ }^{15}$ cubes, ${ }^{16}$ nanowires, ${ }^{17}$ nanocages $^{18,19}$ and various polyhedrons, ${ }^{20}$ and its capability of being used as a template to fabricate various well-defined hollow structures. ${ }^{21} \mathrm{Xu}$ and Xue demonstrated gradual evolutions of $\mathrm{Cu}_{2} \mathrm{O}$ shapes with well-developed facets via reduction 
based on five branching growth patterns. ${ }^{15}$ Organic and inorganic additives (e.g. PVP, CTAB, steric acid, oleic acid and KI) have also been employed as selective surface stabilizers during synthesis to control $\mathrm{Cu}_{2} \mathrm{O}$ growth. ${ }^{14,16,20,22-24}$

The common perspective used to explain photoreactivity variations of $\mathrm{Cu}_{2} \mathrm{O}$ with different exposed facets are (1) surface atomic arrangement resulting in altered adsorption abilities of reactant/product and (2) surface potential-dependent surface electronic band structures. ${ }^{25-28}$ For instance, the highperforming $\mathrm{Cu}_{2} \mathrm{O}$ with $\{110\}$ exposed facet is known to have higher concentrations of copper dangling bonds and favorable surface potentials. ${ }^{20} \mathrm{Chu}$ and Huang also demonstrated the best performance of rhombic dodecahedral $\mathrm{Cu}_{2} \mathrm{O}$ attributed to its ideal surface electronic structure. ${ }^{29}$ To date, various attempts have been devoted to elucidating energy level-shifts of $\mathrm{Cu}_{2} \mathrm{O}$ with distinctive facets through both modelling and experimental approaches. The former involved density functional theory (DFT) calculations while the latter involved the approximation of band structures using techniques such as UVVis, X-ray photoelectron spectroscopy (XPS), ultraviolet photoelectron spectroscopy (UPS) and Mott-Schottky measurements to determine bandgaps, Fermi levels and surface potentials. Due to the complexity in performing direct experimental comparisons of surface adsorption abilities and surface potentials, these parameters are often predicted via density functional theory (DFT) calculations. From a surface electronic structure view point, the shift in surface potentials is believed to affect the dynamics of the charge carriers, such as carrier mobility, lifetime and diffusion length. However, little effort has been invested in evaluating the intrinsic charge dynamic differences of faceted photocatalysts, particularly $\mathrm{Cu}_{2} \mathrm{O}$. In addition to affecting the surface electronic structures, defects that are incorporated within the materials can also have significant influence on the intrinsic carrier dynamics. For instance, oxygen vacancies were introduced into $\mathrm{SrTiO}_{3}$ photocatalyst in reducing atmosphere with low oxygen partial pressure and was shown to induce electron doping, which increases the electron density. The oxygen vacancy density was also quantifiable based on the change in electron density. ${ }^{30}$ Given the commonly used approach to tailor the exposed crystal facets by varying synthesis conditions (e.g. temperature and concentration of precursors/additives), deviations in surface chemistry across samples are unavoidable. As a result, changes to defect concentrations that subsequently modulate intrinsic carrier dynamics are often observed.

Local charge separation plays a decisive role in photocatalysis. For example, local charge separation across microcrystals of $\mathrm{BiVO}_{4}$ was found to be strongly stimulated by facet-selective deposition of cocatalysts and led to a strong increase of oxygen evolution. ${ }^{31}$ Furthermore, Chen et al. has also shown that a dedicated variation of the local defect structure of cubic $\mathrm{Cu}_{2} \mathrm{O}$ microcrystals led to opposite directions of charge separation at a single facet of a $\mathrm{Cu}_{2} \mathrm{O}$ microcrystal. ${ }^{32}$ In order to attain a comprehensive understanding of carrier dynamic differences, we employ time-resolved microwave conductivity (TRMC) measurements to evaluate effective carrier mobility, lifetime and diffusion length. ${ }^{33}$ In addition, modulated surface photovoltage (SPV) measurements are used to assess the spatial separation mechanism of photogenerated charges and their relaxation. The relaxation can last over many orders of magnitude in time, mainly due to transport limitations over barriers and/or trapping. ${ }^{34}$ Therefore, modulated SPV provides complementary information to methods that are only sensitive to free charge carriers, such as TRMC.

Although $\mathrm{Cu}_{2} \mathrm{O}$ surface electronic structures that are interrelated to its intrinsic carrier dynamics have been computed via DFT calculations, experimental verifications of these intrinsic properties play an equally important role to eliminate the possible discrepancies between modelled and actual samples. In this work, cubic and rhombic dodecahedral $\mathrm{Cu}_{2} \mathrm{O}$ with dominant exposed $\{100\}$ and $\{110\}$ facets, respectively, were employed to understand the influence of facet-dependent properties to their photoactivity. The prominent photoactivity of rhombic dodecahedral $\mathrm{Cu}_{2} \mathrm{O}$ in conjunction with its enhanced charge carrier mobility and charge separation signifies the strong influence of carrier dynamics as one of the facetdependent properties. This work pioneers the experimental investigation on $\mathrm{Cu}_{2} \mathrm{O}$ carrier dynamic influence towards photoactivity.

\section{Results and discussions}

\subsection{Photocatalytic performance}

Two $\mathrm{Cu}_{2} \mathrm{O}$ batches with distinct morphologies were fabricated using a facile solution-phase method adapted from Liang et al. ${ }^{5}$ While the surfactant-free synthesis conditions produce uniform cubic $\mathrm{Cu}_{2} \mathrm{O}$ particles (Fig. 1a), the addition of oleic acid as the face-selective adsorption additive favors the growth of rhombic dodecahedral $\mathrm{Cu}_{2} \mathrm{O}$ (Fig. 1c). Observation of the samples at high magnification under a scanning electron microscope (SEM) shows that both samples exhibit a smooth surface as illustrated in Fig. $1 \mathrm{~b}$ and d. Herein, the cubic $\mathrm{Cu}_{2} \mathrm{O}$ particles with six exposed $\{100\}$ facets and the rhombic dodecahedral $\mathrm{Cu}_{2} \mathrm{O}$ particles dominantly enclosed by twelve $\{110\}$ facets are denoted as $\mathrm{CB}-\mathrm{Cu}_{2} \mathrm{O}$ and $\mathrm{RD}-\mathrm{Cu}_{2} \mathrm{O}$, respectively. Note that CB$\mathrm{Cu}_{2} \mathrm{O}$ with sharp edges contains only one type of facet, while $\mathrm{RD}-\mathrm{Cu}_{2} \mathrm{O}$ appears to have other small exposed facets at the corners (i.e. $\{100\}$ facets) of the particles, as illustrated in Fig. 1d. Despite having distinct exposed facets, $\mathrm{CB}-\mathrm{Cu}_{2} \mathrm{O}$ and $\mathrm{RD}-\mathrm{Cu}_{2} \mathrm{O}$ show the same X-ray diffraction (XRD) peaks (Fig. 1e), which correspond to the cubic phase of $\mathrm{Cu}_{2} \mathrm{O}$. The narrow and intense XRD peaks indicate that the two samples have similarly good crystallinity. As inferred by Scherrer's equation, the crystallite sizes were calculated to be $59 \mathrm{~nm}$ for $\mathrm{CB}-\mathrm{Cu}_{2} \mathrm{O}$ and $70 \mathrm{~nm}$ for $\mathrm{RD}-\mathrm{Cu}_{2} \mathrm{O}$. Likewise, both samples display comparable absorption band edges at wavelengths of 615 and $620 \mathrm{~nm}$, as illustrated in their UV-Vis diffuse reflectance spectra (Fig. 1f). The UV-Vis results indicate that $\mathrm{CB}-\mathrm{Cu}_{2} \mathrm{O}$ and $\mathrm{RD}-\mathrm{Cu}_{2} \mathrm{O}$ have a bandgap energy of 2.02 and $2.00 \mathrm{eV}$, respectively, consistent with that reported in the literature. ${ }^{35}$ 

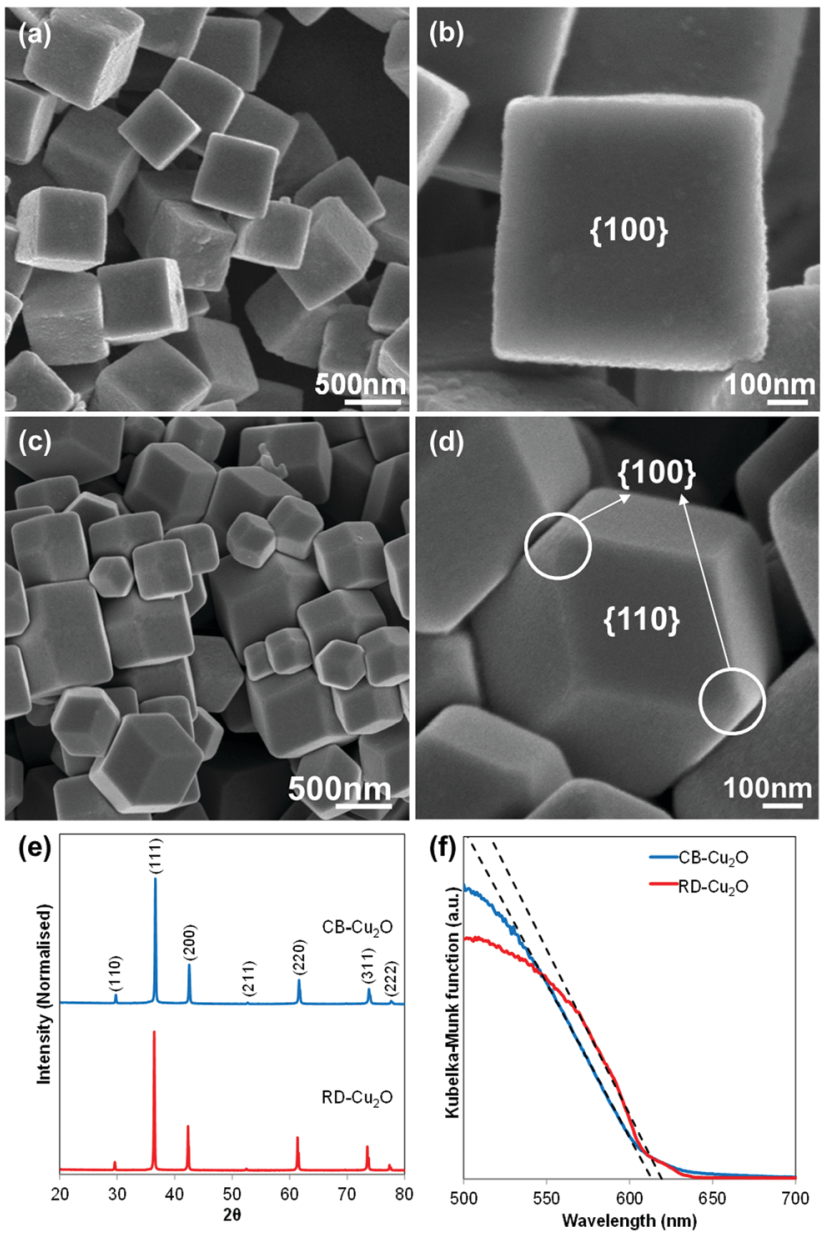

Fig. 1 SEM images of (a and b) cubic $\mathrm{Cu}_{2} \mathrm{O}$ with dominant $\{100\}$ facet, (c and d) rhombic dodecahedral $\mathrm{Cu}_{2} \mathrm{O}$ with dominant $\{110\}$ facet, (e) XRD patterns and (f) UV-Vis absorption spectra of $\mathrm{CB}-\mathrm{Cu}_{2} \mathrm{O}$ and $\mathrm{RD}-\mathrm{Cu}_{2} \mathrm{O}$ converted using Kubelka-Munk transformation.

The photoactivity of $\mathrm{CB}-\mathrm{Cu}_{2} \mathrm{O}$ and $\mathrm{RD}-\mathrm{Cu}_{2} \mathrm{O}$ was compared using photocatalytic (PC) and photoelectrochemical (PEC) approaches. In the $\mathrm{PC}$ system, the $\mathrm{Cu}_{2} \mathrm{O}$ particles were used to induce the reduction of water (i.e. hydrogen $\left(\mathrm{H}_{2}\right)$ evolution) in an aqueous sodium sulfite $\left(\mathrm{Na}_{2} \mathrm{SO}_{3}\right)$ solution. Upon excitation of $\mathrm{Cu}_{2} \mathrm{O}$, the photoinduced holes are effectively scavenged by $\mathrm{SO}_{3}{ }^{2-}$ ions, whereas the photogenerated electrons reduce water to produce gaseous $\mathrm{H}_{2}$. As shown in Fig. 2a, a steady evolution of $\mathrm{H}_{2}$ was observed from both CB- $\mathrm{Cu}_{2} \mathrm{O}$ and $\mathrm{RD}-\mathrm{Cu}_{2} \mathrm{O}$. Careful examination shows that the amount of $\mathrm{H}_{2}$ produced after $6 \mathrm{~h}$ of irradiation for $\mathrm{RD}-\mathrm{Cu}_{2} \mathrm{O}$ with exposed $\{110\}$ facets (i.e. $29.6 \mu \mathrm{mol}$ ) clearly surpasses that of $\mathrm{CB}-\mathrm{Cu}_{2} \mathrm{O}$ with exposed $\{100\}$ facets (i.e. $19.5 \mu \mathrm{mol}$ ). $\mathrm{H}_{2}$ was not detected from the control experiments performed in the absence of light, indicating minimal effect of mechanical stirring during the reaction. Comparison of the $\mathrm{H}_{2}$ generation performance with literatures also shows that the performance is comparable to most of the existing pristine $\mathrm{Cu}_{2} \mathrm{O}$ systems (Table $\mathrm{S} 1, \mathrm{ESI} \dagger$ ). In addition, CB$\mathrm{Cu}_{2} \mathrm{O}$ and $\mathrm{RD}-\mathrm{Cu}_{2} \mathrm{O}$ powders were also made into photoelectrodes. The samples were separately drop-casted onto a conducting FTO substrate to obtain films with a particle density of $2 \mathrm{mg} \mathrm{cm}^{-2}$. Fig. $2 \mathrm{~b}$ displays the photocurrent generated by $\mathrm{CB}-\mathrm{Cu}_{2} \mathrm{O}$ and $\mathrm{RD}-\mathrm{Cu}_{2} \mathrm{O}$ vs. time under chopped illumination, at a constant applied bias of $0.25 \mathrm{~V}$ vs. RHE. The cathodic photocurrents suggest that both $\mathrm{CB}-\mathrm{Cu}_{2} \mathrm{O}$ and $\mathrm{RD}-\mathrm{Cu}_{2} \mathrm{O}$ are ptype semiconductors. Unambiguously, $\mathrm{RD}-\mathrm{Cu}_{2} \mathrm{O}$ exhibits a higher cathodic photocurrent than that of $\mathrm{CB}-\mathrm{Cu}_{2} \mathrm{O}$. Although there exist differences between PC and PEC systems, ${ }^{36,37}$ the significantly enhanced photoactivity of $\mathrm{RD}-\mathrm{Cu}_{2} \mathrm{O}$ in both systems suggests that exposure of both $\{110\}$ and $\{100\}$ facets on $\mathrm{Cu}_{2} \mathrm{O}$ is beneficial when compared to only $\{100\}$ facets. This is also in agreement with other reported literature that demonstrated better photoactivity of $\{110\}$ facets when compared to $\{100\}$ facets. $^{25,26}$

The attention is now shifted to the factors that influence the observed facet-dependent photoactivity of $\mathrm{Cu}_{2} \mathrm{O}$. Both the bulk and surface properties of a semiconductor are known to influence the photoactivity. ${ }^{38,39}$ Since XRD and diffuse reflectance UV-Vis spectroscopy analyses show that $\mathrm{CB}-\mathrm{Cu}_{2} \mathrm{O}$ and RD$\mathrm{Cu}_{2} \mathrm{O}$ have a similar crystal structure, crystallinity and bandgap energy, the influence of these properties in determining the photoactivity can be disregarded. The possible contribution of different specific surface area can also be eliminated given that the better-performing $\mathrm{RD}-\mathrm{Cu}_{2} \mathrm{O}$ has a BET surface area of $1.6 \mathrm{~m}^{2} \mathrm{~g}^{-1}$, which is half of that of $\mathrm{CB}-\mathrm{Cu}_{2} \mathrm{O}\left(3.2 \mathrm{~m}^{2} \mathrm{~g}^{-1}\right)$. Therefore, the different photoactivity of $\mathrm{CB}-\mathrm{Cu}_{2} \mathrm{O}$ and $\mathrm{RD}-\mathrm{Cu}_{2} \mathrm{O}$ in $\mathrm{PC} \mathrm{H}_{2}$ evolution and PEC photocurrent generation can be attributed to the difference in the exposed facets. Several factors have been recently demonstrated to be dependent on the types of exposed facets: (1) the corrosion tendency, (2) the surface adsorption ability that relies on the surface atomic arrangement and (3) the charge transfer efficiency that is known to be affected by the variation of the surface electronic structure. ${ }^{40}$ Our previous work revealed that the dominant photocorrosion pathway for $\mathrm{Cu}_{2} \mathrm{O}$ in a PC system is selfphotooxidation into $\mathrm{CuO}^{41}$ In that study, we showed that the presence of a strong hole scavenger (i.e. $\mathrm{Na}_{2} \mathrm{SO}_{3}$ ) has not only improved the photocatalytic $\mathrm{H}_{2}$ evolution rate, photocorrosion of $\mathrm{Cu}_{2} \mathrm{O}$ has also been efficiently suppressed due to the rapid consumption of photogenerated holes that could otherwise be consumed for self-oxidation of $\mathrm{Cu}_{2} \mathrm{O}$. Given that $\mathrm{Na}_{2} \mathrm{SO}_{3}$ was employed as a sacrificial reagent in this work, the difference in the corrosion tendencies between the two $\mathrm{Cu}_{2} \mathrm{O}$ samples with distinct exposed facets can be assumed to be minimal. The stability of the samples has also been tested with detailed information provided in the Fig. S1 (ESI $\dagger$ ). As illustrated in Fig. S1c (ESI $\dagger$ ), the performance of $\mathrm{RD}-\mathrm{Cu}_{2} \mathrm{O}$ was retained at more than $80 \%$ after the third cycle of reaction.

\subsection{Surface atomic structure}

DFT calculations were employed to model the $\mathrm{Cu}_{2} \mathrm{O}\{100\}$ and $\{110\}$ surfaces, as analogues to $\mathrm{CB}-\mathrm{Cu}_{2} \mathrm{O}$ and $\mathrm{RD}-\mathrm{Cu}_{2} \mathrm{O}$ facets, respectively. These surfaces can host a number of defects arising from their distinct surface features. These have been modelled and characterized extensively by Soon et al., ${ }^{42}$ in which their surface nomenclatures for assigning surface 

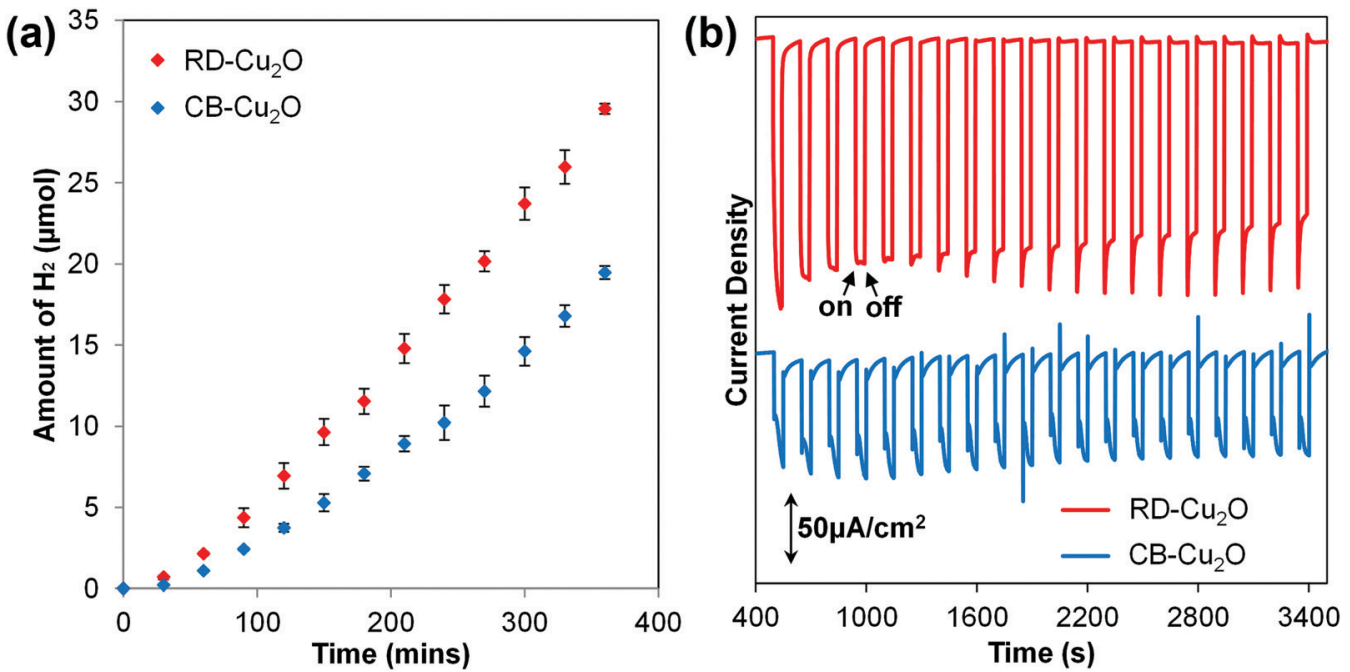

Fig. 2 (a) Time course of photocatalytic $\mathrm{H}_{2}$ evolution during 6 hours of illumination and (b) PEC amperometric photocurrent densities of $\mathrm{CB}-\mathrm{Cu} \mathrm{u}_{2} \mathrm{O}$ and $\mathrm{RD}-\mathrm{Cu}_{2} \mathrm{O}$.

defects are followed here. Each surface can exist with several different terminations $(\mathrm{Cu}, \mathrm{O}$ and $\mathrm{CuO})$, along with a number of native surface defects such as $\mathrm{Cu}$ or $\mathrm{O}$ vacancies and interstitials. Fig. 3a shows the atomic models of surfaces that were chosen from a set of structures with the lowest surface free energies within the range of experimentally achievable oxygen chemical pressure. ${ }^{42}$ The adsorption energies of $\mathrm{H}, \mathrm{H}_{2}$ and $\mathrm{H}_{2} \mathrm{O}$ were obtained at different surface sites (Fig. $3 \mathrm{~b}$ ), with no clear trend observed. In general, $\mathrm{H}$ shows a strong preference to bind on $\mathrm{O}$ sites compared to $\mathrm{Cu}$ sites. In some cases, $\mathrm{H}$ binding energies are comparable, as illustrated by $\mathrm{Cu}_{2} \mathrm{O}\{100\}_{\mathrm{O}}$ and $\mathrm{Cu}_{2} \mathrm{O}\{110\}_{\mathrm{CuO}^{-}}-\mathrm{Cu}_{\mathrm{csa}} @ \mathrm{O}$ sites $(-2.24 \mathrm{eV}$ and $-2.41 \mathrm{eV}$, respectively). On the other hand, $\mathrm{H}_{2}$ binding is less sensitive to the surface details and binds with similar strengths on $\mathrm{Cu}$ and $\mathrm{O}$ sites. The difficulty to experimentally distinguish the existence of various surface terminations under ambient conditions complicates the comparison of surface adsorption abilities. One can assume that the two surfaces with relatively similar surface free energies will coexist. Hence, the adsorption abilities of $\mathrm{H}, \mathrm{H}_{2}$ and $\mathrm{H}_{2} \mathrm{O}$ should not be very different from (a)
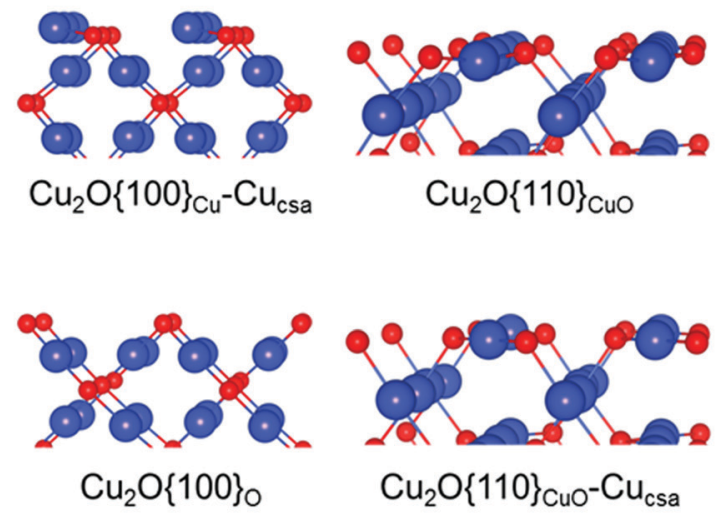

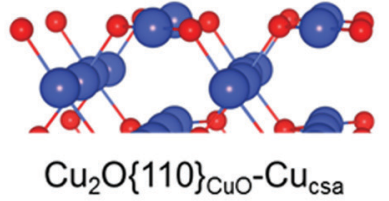

(b)

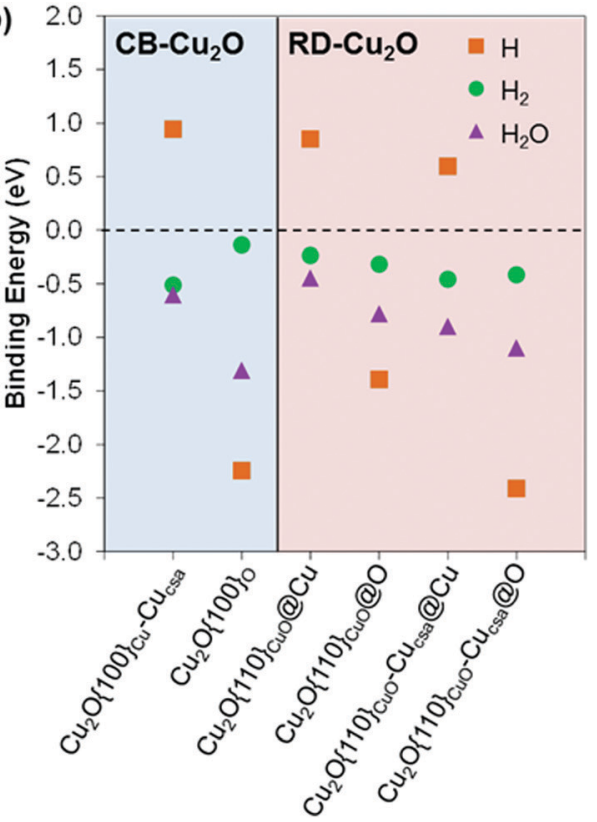

Fig. 3 (a) Atomic arrangement of thermodynamically stable $\mathrm{Cu}_{2} \mathrm{O}\{100\}$ and $\{110\}$ exposed facet with distinctive terminating surface, blue represents $\mathrm{Cu}$ atom and red represents $\mathrm{O}$ atom, and (b) modelled surface adsorption ability of $\mathrm{H}, \mathrm{H}_{2}$ and $\mathrm{H}_{2} \mathrm{O}$ of $\mathrm{Cu}_{2} \mathrm{O}\{100\}$ and $\{110\} . \mathrm{Cu}_{2} \mathrm{O}\{100\} \mathrm{Cu}^{-} \mathrm{Cu}_{\mathrm{csa}}$ : $\mathrm{Cu}_{-}$ terminated $\mathrm{Cu}_{2} \mathrm{O}\{100\}$ with a coordinatively saturated $\mathrm{Cu}$ removed, $\mathrm{Cu}_{2} \mathrm{O}\{100\}$ o: O-terminated $\mathrm{Cu}_{2} \mathrm{O}\{100\}, \mathrm{Cu}_{2} \mathrm{O}\{110\} \mathrm{CuO}$ : $\mathrm{CuO}$-terminated $\mathrm{Cu}_{2} \mathrm{O}\{110\}$ and $\mathrm{Cu}_{2} \mathrm{O}\{110\}_{\mathrm{CuO}}-\mathrm{Cu}_{\mathrm{csa}}$ : $\mathrm{CuO}$-terminated $\mathrm{Cu}_{2} \mathrm{O}\{110\}$ with coordinatively saturated $\mathrm{Cu}$ removed. The $@ \mathrm{O}$ and $@ \mathrm{Cu}$ denotes adsorption at $\mathrm{O}$ and $\mathrm{Cu}$ active sites, respectively. 
$\mathrm{CB}-\mathrm{Cu}_{2} \mathrm{O}$ and $\mathrm{RD}-\mathrm{Cu}_{2} \mathrm{O}$. The above explanation is based on the adsorbate binding energies (Fig. 3b) obtained in the low coverage regime. At high coverages where all active sites are occupied, the $\mathrm{H}^{*}$ free energy of $\mathrm{Cu}_{2} \mathrm{O}\{110\}_{\text {CuO }}$ surface $(-0.3 \mathrm{eV})$ is relatively closer to the ideal adsorption energy of $0 \mathrm{eV}$, when compared to $-1.85 \mathrm{eV}$ and $-1.77 \mathrm{eV}$ for $\mathrm{Cu}_{2} \mathrm{O}\{100\}_{\mathrm{O}}$ and $\mathrm{Cu}_{2} \mathrm{O}\{110\}_{\mathrm{CuO}^{-}} \mathrm{Cu}_{\mathrm{csa}} @ \mathrm{O}$, respectively (Fig. S2, ESI $\dagger$ ). This indirectly indicates a better adsorption of $\mathrm{H}^{*}$ on $\mathrm{RD}-\mathrm{Cu}_{2} \mathrm{O}$ with high $\mathrm{H}_{2}$ evolution efficiency.

\subsection{Surface electronic structure}

In the case of surface electronic structure, variations in band structure have been demonstrated to influence the intrinsic carrier dynamics of a semiconductor. A first insight in the differences in surface electronic structure of $\mathrm{CB}-\mathrm{Cu}_{2} \mathrm{O}$ and $\mathrm{RD}$ $\mathrm{Cu}_{2} \mathrm{O}$ can be obtained by correlating the measured bandgap to their respective valence band positions determined from linear sweep voltammetry (LSV, to determine the on-set potential) and valence band XPS measurements. ${ }^{11}$ The onset potential for a p-type semiconductor is defined as the most positive potential at which the cathodic photocurrent still coincides with the dark current. $^{43}$ These values (i.e. +0.59 and $+0.69 \mathrm{~V}$ vs. RHE for CB$\mathrm{Cu}_{2} \mathrm{O}$ and $\mathrm{RD}-\mathrm{Cu}_{2} \mathrm{O}$, as tabulated in Table $\mathrm{S} 2$, ESI $\dagger$ ) are obtained from LSV measurements under chopped irradiation (Fig. S3a, ESI $\dagger$ ) and can be used as a first-order approximation of their corresponding flat band potentials. ${ }^{44}$ In addition, valence band XPS (Fig. S3b, ESI $\dagger$ ) was conducted to measure the potential difference between the valence band maxima and the Fermi levels. ${ }^{11}$ From extrapolation, the valence band of $\mathrm{CB}-\mathrm{Cu}_{2} \mathrm{O}$ and $\mathrm{RD}-\mathrm{Cu}_{2} \mathrm{O}$ are determined to lie at +0.94 and $+1.00 \mathrm{~V}$ vs. RHE, respectively. Subsequently, the conduction band positions were calculated by adding the band gap energies to the valence band positions, resulting in values of $-1.08 \mathrm{~V}$ for $\mathrm{CB}-\mathrm{Cu}_{2} \mathrm{O}$ and $-1.00 \mathrm{~V}$ for $\mathrm{RD}-\mathrm{Cu}_{2} \mathrm{O}$, both with respect to RHE. All these band position values are compiled to give schematic band structures as illustrated in Fig. 4a (also tabulated in Table S2, ESI $\dagger$ ).

Fig. 4a shows that the Fermi levels of both samples are closer to the valence band than to the conduction band, which again confirms the p-type nature of both $\mathrm{Cu}_{2} \mathrm{O}$ samples. The conduction and valence bands of the rhombic dodecahedral $\{110\}$-dominated sample $\left(\mathrm{RD}-\mathrm{Cu}_{2} \mathrm{O}\right)$ are located at a more positive position when compared to the cubic $\{100\}$-faceted $\mathrm{Cu}_{2} \mathrm{O}\left(\mathrm{CB}-\mathrm{Cu}_{2} \mathrm{O}\right)$, in agreement with the literature. ${ }^{45}$ This surface potential shift is often deduced as one of the factors governing the carrier transfer efficiency and thus, enhancing the photoactivity. When the samples are in contact with an electrolyte, the semiconductor/electrolyte junctions were formed due to the difference in potentials between the semiconductors and the electrolyte. After the equilibration of these interfaces, a downward band bending ( $\mathrm{V}_{\mathrm{bb}}$, for $\mathrm{p}$-type semiconductor) is created, as demonstrated in Fig. $4 \mathrm{~b}$. This potential gradient enhances the carrier separation efficiency and thereby increases the fraction of photoexcited electrons that arrives at the surface. Since the Fermi level of $\mathrm{RD}-\mathrm{Cu}_{2} \mathrm{O}$ is located at a more positive potential, the equilibration leads to a higher degree of band bending (Fig. 4b). Although the difference is relatively small, the larger band bending of $\mathrm{RD}-\mathrm{Cu}_{2} \mathrm{O}$ is often a typical reason used to justify the better PC and PEC performance, owing to the improved charge transfer for photoreduction. $^{46}$

\subsection{Defect density}

Apart from surface atomic structures and surface electronic structures, defect density is another property that may be tuned when synthesizing $\mathrm{Cu}_{2} \mathrm{O}$ with different exposed facets. To evaluate the defect density, XPS investigations were performed on $\mathrm{CB}-\mathrm{Cu}_{2} \mathrm{O}$ and $\mathrm{RD}-\mathrm{Cu}_{2} \mathrm{O}$ samples. The $\mathrm{O} 1 \mathrm{~s}$ spectra (Fig. 5a) show the presence of three distinct oxygen species: lattice (a)

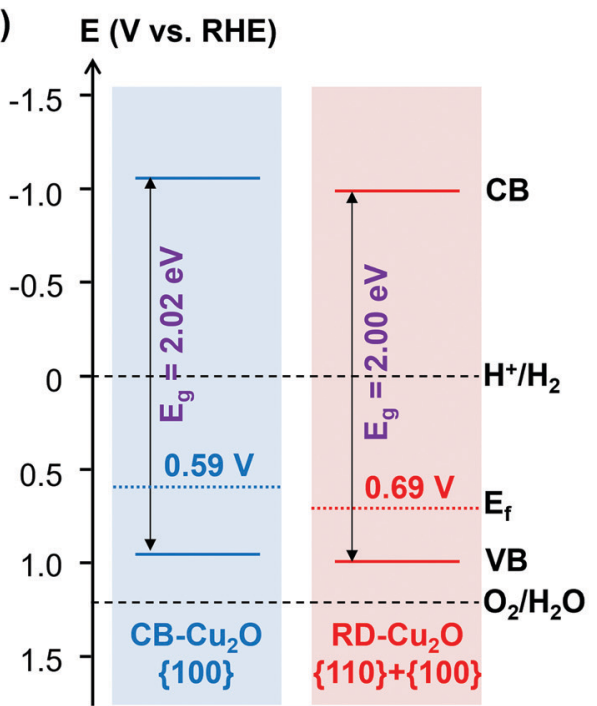

(b)
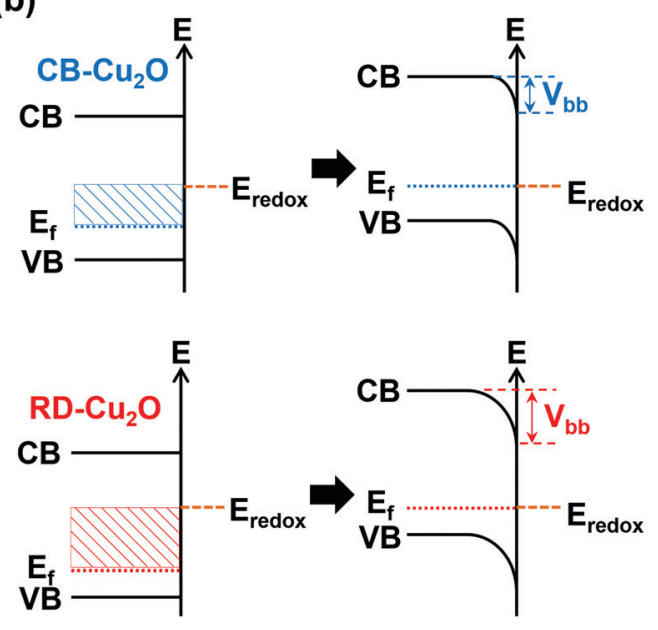

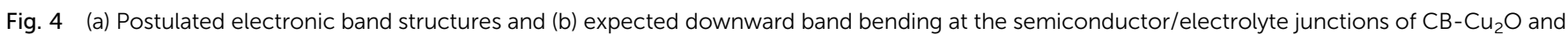
$\mathrm{RD}-\mathrm{Cu}_{2} \mathrm{O}$. 
(a)

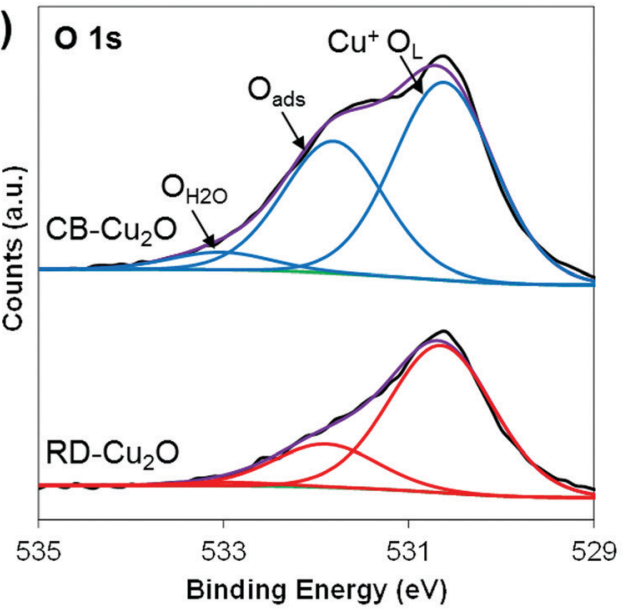

(c)

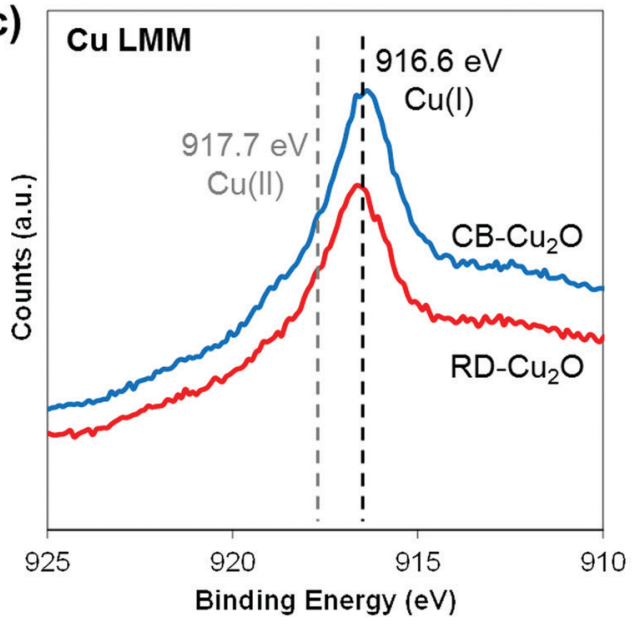

(b)

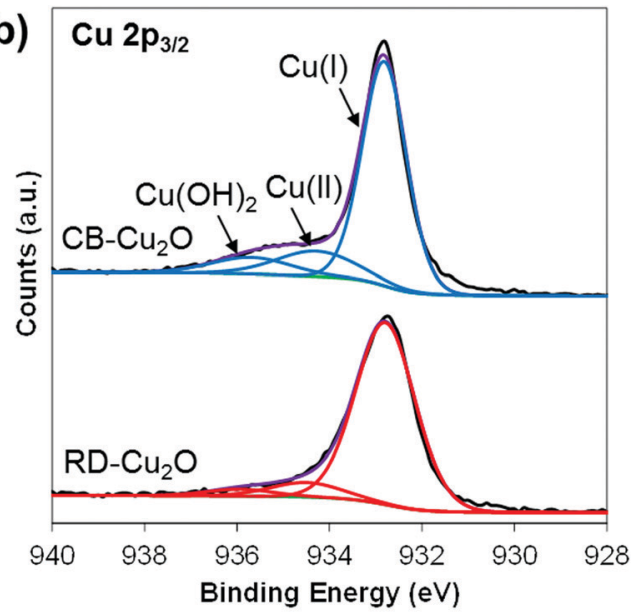

(d)

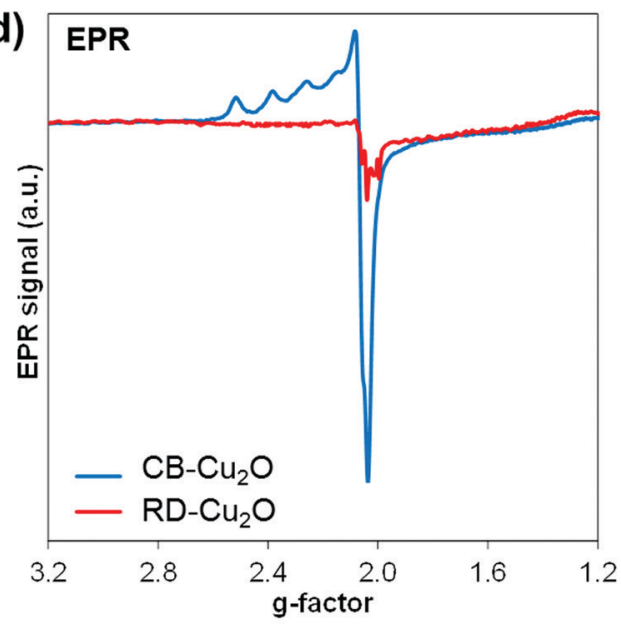

Fig. 5 (a) O1s, (b) $C u 2 p_{3 / 2}$, (c) $\mathrm{Cu} L M M$ spectra from XPS measurement and (d) EPR spectra for $C B-\mathrm{Cu}_{2} \mathrm{O}$ and $\mathrm{RD}-\mathrm{Cu}_{2} \mathrm{O}$.

oxygen of $\mathrm{Cu}_{2} \mathrm{O}\left(\mathrm{Cu}^{+} \mathrm{O}_{\mathrm{L}}\right)$, adsorbed oxygen $\left(\mathrm{O}_{\text {ads }}\right)$ and oxygen from water vapor/moisture $\left(\mathrm{O}_{\mathrm{H}_{2} \mathrm{O}}\right)$ with their corresponding peaks at the binding energies of 530.6, 531.9 and $533.0 \mathrm{eV}$, respectively. ${ }^{47}$ Considering that $\mathrm{O}_{\text {ads }}$ is associated with oxygen vacancies, ${ }^{48}$ the larger peak area of $\mathrm{O}_{\text {ads }}$ shown by $\mathrm{CB}-\mathrm{Cu}_{2} \mathrm{O}$ indicates that this sample contains more surface oxygen vacancies than $\mathrm{RD}-\mathrm{Cu}_{2} \mathrm{O}$. For $\mathrm{Cu} 2 \mathrm{p}_{3 / 2}$ spectra (Fig. $5 \mathrm{~b}$ ), in addition to the dominant peak at $932.8 \mathrm{eV}$ that corresponds to $\mathrm{Cu}(\mathrm{I})$ oxidation state of $\mathrm{Cu}_{2} \mathrm{O}$, two peaks at higher binding energies (934.4 and $935.8 \mathrm{eV}$ ) which are ascribed to $\mathrm{Cu}(\mathrm{II})$ oxidation state and $\mathrm{Cu}(\mathrm{OH})_{2}$ are also observed in both samples. ${ }^{49,50}$ Note that the copper species at $934.4 \mathrm{eV}\left(\mathrm{Cu}^{2+}\right)$ is attributed to the presence of a copper defect rather than to $\mathrm{CuO}$, given that only a single peak at $916.6 \mathrm{eV}$ related to $\mathrm{Cu}_{2} \mathrm{O}$ was detected from the $\mathrm{Cu}$ LMM Auger spectra (Fig. 5c). ${ }^{51}$ The higher intensity of the $\mathrm{Cu}^{2+}$ peak for $\mathrm{CB}-\mathrm{Cu}_{2} \mathrm{O}$ suggests that it contains a higher concentration of copper defects when compared to $\mathrm{RD}-\mathrm{Cu}_{2} \mathrm{O}$. This is further confirmed by electron paramagnetic resonance (EPR) spectroscopy. Since $\mathrm{Cu}^{2+}$ is a paramagnetic species, the presence of copper deficiencies can be detected using EPR. Indeed, an EPR signal at a $g$-value of 2.06 corresponding to $\mathrm{Cu}^{2+}$ was observed for both samples, as illustrated in Fig. $5 \mathrm{~d} .^{52}$
The more intense EPR signals of $\mathrm{CB}-\mathrm{Cu}_{2} \mathrm{O}$ demonstrate the existence of a higher amount of copper defects, consistent with the XPS data. Overall, the XPS and EPR results convincingly show that $\mathrm{CB}-\mathrm{Cu}_{2} \mathrm{O}$ has more structural defects (i.e. oxygen vacancies and copper deficiencies) than $\mathrm{RD}-\mathrm{Cu}_{2} \mathrm{O}$. This indicates that apart from surface atomic structures and surface electronic structures, the nature and concentration of defects should be considered as one of the facet-dependent properties that should not be overlooked.

\subsection{Carrier dynamics}

Both $\mathrm{CB}-\mathrm{Cu}_{2} \mathrm{O}$ and $\mathrm{RD}-\mathrm{Cu}_{2} \mathrm{O}$ exhibit distinct facet-dependent properties as mentioned above. Nonetheless, the dominant governing factors that dictate photocatalytic performance are often related to the intrinsic charge dynamics, which are also affected by changes in the above-mentioned facet-dependent properties (i.e. surface electronic structure and defect density). In order to gain insight into $\mathrm{Cu}_{2} \mathrm{O}$ carrier dynamics, timeresolved microwave conductivity (TRMC), photoluminescence (PL) and surface photovoltage spectroscopy (SPV) measurements were conducted on $\mathrm{CB}-\mathrm{Cu}_{2} \mathrm{O}$ and $\mathrm{RD}-\mathrm{Cu}_{2} \mathrm{O}$. 

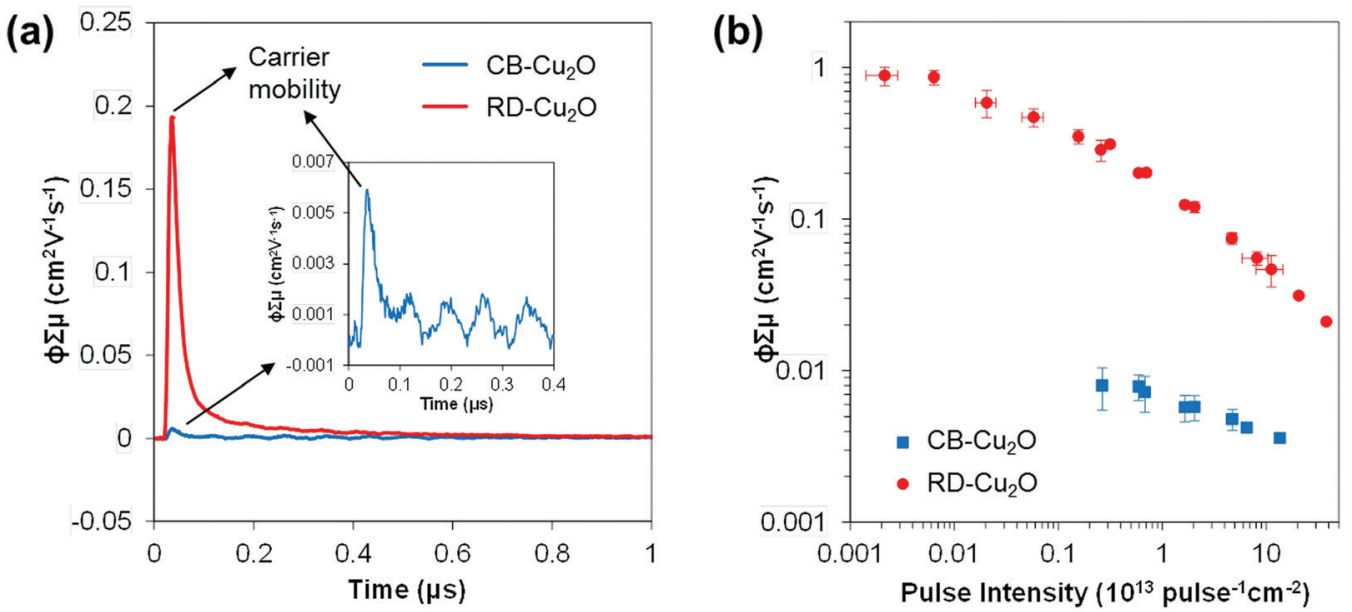

Fig. 6 (a) TRMC signal of $\mathrm{CB}-\mathrm{Cu}_{2} \mathrm{O}$ and $\mathrm{RD}-\mathrm{Cu}_{2} \mathrm{O}$ over time at $7.0 \times 10^{12}$ photons pulse ${ }^{-1} \mathrm{~cm}^{-2}$, with the inset showing the magnification of the signal of $\mathrm{CB}-\mathrm{Cu}_{2} \mathrm{O}$, and $(\mathrm{b})$ maximum TRMC signal as a function of incident pulse intensity of $\mathrm{CB}-\mathrm{Cu}_{2} \mathrm{O}$ and $\mathrm{RD}-\mathrm{Cu}_{2} \mathrm{O}$.

TRMC is a contactless technique for measuring the photoconductivity of a semiconductor. The data can then be used to determine the sum of the charge carrier mobilities $\left(\sum \mu\right)$ and the effective lifetime ( $\left.\tau_{\text {eff }}\right)$ of the carriers. The TRMC system utilizes a nanosecond pulsed laser to excite the sample which generates mobile carriers (i.e. electrons and holes) that modify the reflected microwave power. ${ }^{53,54}$ Fig. $6 \mathrm{a}$ shows the microwave conductance transients of $\mathrm{CB}-\mathrm{Cu}_{2} \mathrm{O}$ and $\mathrm{RD}-\mathrm{Cu}_{2} \mathrm{O}$ obtained after excitation with a $355 \mathrm{~nm}$ laser pulse of $7.0 \times$ $10^{12}$ photons pulse $\mathrm{cm}^{-2}$. While $\mathrm{CB}-\mathrm{Cu}_{2} \mathrm{O}$ achieves a maximum TRMC signal (i.e. $\phi \sum \mu$, see Experimental section for definition) of $0.006 \mathrm{~cm}^{2} \mathrm{~V}^{-1} \mathrm{~s}^{-1}$, the signal for $\mathrm{RD}-\mathrm{Cu}_{2} \mathrm{O}$ is larger by almost two orders of magnitude $\left(0.19 \mathrm{~cm}^{2} \mathrm{~V}^{-1} \mathrm{~s}^{-1}\right)$. TRMC measurements with varying laser pulse intensities also confirm that $\mathrm{RD}-\mathrm{Cu}_{2} \mathrm{O}$ consistently exhibits much higher maximum $\phi \sum \mu$ values than $\mathrm{CB}-\mathrm{Cu}_{2} \mathrm{O}$, as portrayed in Fig. $6 \mathrm{~b}$. Note that the decrease of $\phi \sum \mu$ with increasing laser pulse intensity is attributed to higher-order non-geminate electron-hole recombination..$^{55,56}$ The reduced recombination at lower light intensities thus contributes to the plateau (intensityindependent $\phi \sum \mu$ ) that is observed, particularly for $\mathrm{RB}^{-\mathrm{Cu}_{2} \mathrm{O}}$ at the region of low laser pulse intensities. Since the maximum $\phi \sum \mu$ can be taken as a representative value of the effective carrier mobility in a semiconductor, the results suggest that $\mathrm{RD}-\mathrm{Cu}_{2} \mathrm{O}$ has substantially higher carrier mobility when compared to that of $\mathrm{CB}-\mathrm{Cu}_{2} \mathrm{O}$. The remarkably higher carrier mobility of $\mathrm{RD}-\mathrm{Cu}_{2} \mathrm{O}$ is also validated by the good signal-tonoise ratio generated with a laser pulse intensity as low as $2.0 \times 10^{10}$ photons pulse ${ }^{-1} \mathrm{~cm}^{-2}$, while clear photoconductance signals for $\mathrm{CB}-\mathrm{Cu}_{2} \mathrm{O}$ can only be obtained at higher laser pulse intensities $\left(>10^{12}\right.$ photons pulse $\mathrm{cm}^{-1}$ ). Similar trends are observed for TRMC measurements at $532 \mathrm{~nm}$ laser pulse irradiation (Fig. S4, ESI $\dagger$ ), which again confirms the excellent carrier mobility of $\mathrm{RD}-\mathrm{Cu}_{2} \mathrm{O}$ in comparison to $\mathrm{CB}-\mathrm{Cu}_{2} \mathrm{O}$. This finding is also in accordance with the recently reported TRMC measurements of $\mathrm{Cu}_{2} \mathrm{O}$, demonstrating a much higher charge mobility of polyhedral $\mathrm{Cu}_{2} \mathrm{O}$ when compared to cubic $\mathrm{Cu}_{2} \mathrm{O}^{57}$
The effective carrier lifetimes of the two $\mathrm{Cu}_{2} \mathrm{O}$ samples were determined from the decay of their TRMC signals as shown in Fig. 6a. Each of the curves can be well-fitted to a bi-exponential decay, in which the derived decay time constants $\left(\tau_{1}\right.$ and $\left.\tau_{2}\right)$ are tabulated in Table 1 . Both the $\tau_{1}$ and $\tau_{2}$ for $\mathrm{CB}-\mathrm{Cu}_{2} \mathrm{O}$ are smaller than that of $\mathrm{RD}-\mathrm{Cu}_{2} \mathrm{O}$, suggesting that the charge carriers recombine/trap faster in $\mathrm{CB}-\mathrm{Cu}_{2} \mathrm{O}$. This is attributed to the presence of more structural defects in this sample, as validated by the XPS and EPR analyses results above. Such structural defects are reported to be associated with the trapping of carriers, thereby acting as a deleterious charge recombination sites. ${ }^{38}$ Based on the obtained effective carrier mobility and lifetime $\left(\tau_{\mathrm{eff}}\right)$, the effective carrier diffusion length $\left(L_{\mathrm{D} \text {,eff }}\right)$ of CB$\mathrm{Cu}_{2} \mathrm{O}$ and $\mathrm{RD}-\mathrm{Cu}_{2} \mathrm{O}$ were estimated according to eqn (1) and (2).

$$
\begin{gathered}
D=\frac{k T}{e} \mu \\
L_{\mathrm{D}, \mathrm{eff}}=\sqrt{D \tau_{\text {eff }}}
\end{gathered}
$$

where $D$ is the diffusivity, $k$ is the Boltzmann constant, $T$ is the temperature in Kelvin and $e$ is the elementary charge, $1.602 \times$ $10^{-19} \mathrm{C}$. Since the carriers in $\mathrm{RD}-\mathrm{Cu}_{2} \mathrm{O}$ are more mobile and have longer lifetimes, the effective carrier diffusion lengths for $\mathrm{RD}-\mathrm{Cu}_{2} \mathrm{O}$ are longer than those for $\mathrm{CB}-\mathrm{Cu}_{2} \mathrm{O}$ (Table 1).

Apart from that, dark microwave conductivity measurements (refer to ESI $\dagger$ for detailed calculations) were also performed to determine the conductivity $(\sigma)$ and carrier density $\left(N_{\mathrm{a}}\right)$ of $\mathrm{CB}-\mathrm{Cu}_{2} \mathrm{O}$ and $\mathrm{RD}-\mathrm{Cu}_{2} \mathrm{O} \cdot{ }^{58}$ As tabulated in Table S3 (ESI $\dagger$ ), $\mathrm{CB}-\mathrm{Cu}_{2} \mathrm{O}$ has a higher carrier density and thus a higher

Table 1 Average effective charge lifetime and diffusion length of CB$\mathrm{Cu}_{2} \mathrm{O}$ and $\mathrm{RD}-\mathrm{Cu}_{2} \mathrm{O}$

\begin{tabular}{lllllr}
\hline & \multicolumn{2}{l}{ Carrier lifetime, $\tau_{\text {eff }}(\mathrm{ns})$} & & \multicolumn{2}{c}{ Diffusion length, $L_{\mathrm{D}, \text { eff }}(\mathrm{nm})$} \\
\cline { 2 - 3 } \cline { 5 - 6 } Samples & $\tau_{1}$ & $\tau_{2}$ & & From $\tau_{1}$ & \multicolumn{1}{c}{ From $\tau_{2}$} \\
\hline $\mathrm{CB}-\mathrm{Cu}_{2} \mathrm{O}$ & $14.3 \pm 1.5$ & $257.0 \pm 8.8$ & & $14.7 \pm 0.7$ & $63.2 \pm 11.4$ \\
$\mathrm{RD}-\mathrm{Cu}_{2} \mathrm{O}$ & $22.2 \pm 4.0$ & $281.0 \pm 9.1$ & & $97.9 \pm 10.3$ & $280.9 \pm 38.7$
\end{tabular}


conductivity than $\mathrm{RD}-\mathrm{Cu}_{2} \mathrm{O}$. This can be explained by the existence of a higher concentration of defects in $\mathrm{CB}-\mathrm{Cu}_{2} \mathrm{O}$, which typically contribute to electron trapping. This increases the $N_{\mathrm{a}}$ and accordingly the $\sigma$, based on eqn (3).

$$
\sigma=e N_{\mathrm{a}} \mu
$$

where $e$ is the elementary charge. This is further supported by the lower resistance detected in $\mathrm{CB}-\mathrm{Cu}_{2} \mathrm{O}$ when compared to $\mathrm{RD}-\mathrm{Cu}_{2} \mathrm{O}$ during a four-point probe resistivity measurement (results not shown here because the resistivity of $\mathrm{RD}-\mathrm{Cu}_{2} \mathrm{O}$ is larger than the detection limit of the voltmeter used). Such phenomenon is in accordance with the inverse correlation between $\sigma$ and resistivity $(\rho)$ :

$$
\sigma=\frac{1}{\rho}
$$

This finding fits perfectly with the finding of Tan and coworkers, in which cubic $\mathrm{Cu}_{2} \mathrm{O}$ was found to be moderately conductive while rhombic dodecahedral $\mathrm{Cu}_{2} \mathrm{O}$ were shown to be nonconductive. ${ }^{59}$

The extent of electron-hole pair recombination in $\mathrm{CB}-\mathrm{Cu}_{2} \mathrm{O}$ and $\mathrm{RD}-\mathrm{Cu}_{2} \mathrm{O}$ was also studied with steady-state photoluminescence (PL) spectroscopy. Although an emission band at $615 \mathrm{~nm}$, which corresponds to band-to-band recombination, are exhibited by both types of $\mathrm{Cu}_{2} \mathrm{O}$, the PL intensity of $\mathrm{CB}-\mathrm{Cu}_{2} \mathrm{O}$ is noticeably higher than that of $\mathrm{RD}-\mathrm{Cu}_{2} \mathrm{O}$ (Fig. S5, ESI $\dagger$ ). This implies that the rate of band-to-band recombination is higher than that of $\mathrm{RD}-\mathrm{Cu}_{2} \mathrm{O}$. This therefore indicates that the higher defect concentration leads to poor charge separation of CB$\mathrm{Cu}_{2} \mathrm{O}$, which is detrimental to the overall performance, in accordance with its shorter effective carrier lifetime deduced from the TRMC decay curve. Collectively, despite having higher carrier density, the photoactivity in PC and PEC systems of conductive $\mathrm{CB}-\mathrm{Cu}_{2} \mathrm{O}$ is hindered by its significantly lower carrier mobility and shorter carrier lifetime.

In addition to TRMC and PL spectroscopy, modulated surface photovoltage (SPV) spectroscopy measurements were performed to distinguish the dominating mechanism of charge separation and relaxation in $\mathrm{CB}-\mathrm{Cu}_{2} \mathrm{O}$ and $\mathrm{RD}-\mathrm{Cu}_{2} \mathrm{O}$. In contrast to our expectation, the SPV signals for the $\mathrm{RD}-\mathrm{Cu}_{2} \mathrm{O}$ sample (larger band bending) are not larger than those of the $\mathrm{CB}-\mathrm{Cu}_{2} \mathrm{O}$ sample; instead, $\mathrm{CB}-\mathrm{Cu}_{2} \mathrm{O}$ showed up to 2 orders of magnitude higher SPV signals than RD- $\mathrm{Cu}_{2} \mathrm{O}$ (Fig. 7a, b and Fig. S6, ESI $\dagger$ ) at different modulation frequencies. This observation is unlikely to be the result of the surface band bending difference as discussed above. Alternatively, the SPV spectra provide further information of the presence of surface trap states (i.e. defects, as confirmed by XPS and EPR) that are shown to be detectable by SPV spectroscopy, ${ }^{60,61}$ and dominating mechanisms of charge separation in $\mathrm{CB}-\mathrm{Cu}_{2} \mathrm{O}$ and $\mathrm{RD}-\mathrm{Cu}_{2} \mathrm{O}$ (as explained below). As previously reported, a higher copper deficiency $\left(\mathrm{Cu}^{2+}\right)$ results in stronger negative in-phase SPV signals, ${ }^{32}$ which is in accordance to the intense SPV signals of $\mathrm{CB}-\mathrm{Cu}_{2} \mathrm{O}$ that possesses higher defect density when compared to RD$\mathrm{Cu}_{2} \mathrm{O}$.
Fig. S6 (ESI $\dagger$ ) shows the modulated SPV spectra of in-phase and $90^{\circ}$ phase-shifted signals of $\mathrm{CB}-\mathrm{Cu}_{2} \mathrm{O}$ and $\mathrm{RD}-\mathrm{Cu}_{2} \mathrm{O}$ measured at 5, 15 and $80 \mathrm{~Hz}$. The negative in-phase signal indicates that photogenerated electrons are separated preferentially towards the external surface, similar to the phenomenon observed by Chen et al. ${ }^{5}$ For CB-Cu ${ }_{2} \mathrm{O}$ (Fig. S6a, ESI $\dagger$ ), the SPV signals start to appear at approx. $1 \mathrm{eV}$ and further intensified at $2 \mathrm{eV}$ (band gap of $\mathrm{Cu}_{2} \mathrm{O}$ ). The emergence of the signal at lower photon energies $(<2 \mathrm{eV})$ is due to the presence of defects in CB$\mathrm{Cu}_{2} \mathrm{O}$, consistent with our XPS and EPR results. The dependencies of the SPV amplitudes on the modulation frequency are depicted in Fig. 7(a) and (b) for photon energies of 1.8, 2.0, 2.5 and $2.7 \mathrm{eV}$ (i.e. in the ranges below the band gap, near the band gap, in the local minimum and near the second maximum, respectively, refer to $\mathrm{ESI} \dagger$ for detailed explanation). In contrast to $\mathrm{CB}-\mathrm{Cu}_{2} \mathrm{O}$, the highest SPV amplitudes are reached for RD$\mathrm{Cu}_{2} \mathrm{O}$ at a photon energy of $2.0 \mathrm{eV}$ and the SPV amplitudes do not decrease monotonously with increasing frequency, as illustrated in Fig. 7b. In order to understand the dominating mechanisms of charge separation in $\mathrm{CB}-\mathrm{Cu}_{2} \mathrm{O}$ and $\mathrm{RD}-\mathrm{Cu}_{2} \mathrm{O}$, the dependencies of the amplitudes for the "fast" $\left(\mathrm{A}_{1}\right)$ and "slow" $\left(A_{2}\right)$ processes are calculated by fitting Fig. 7a and b to their corresponding functions described by eqn (S4) and (S5) (ESI $\dagger$ ), respectively. $A_{1}$ and $A_{2}$ are compared as a function of the (qualitative) absorption range. Photons with energies at $1.8 \mathrm{eV}$ represent the absorption by transitions from defect states into the conduction or valence bands of $\mathrm{Cu}_{2} \mathrm{O}$, while the absorption lengths $(1 / \alpha)$ at the photon energies of $2.0,2.5$ and $2.7 \mathrm{eV}$ are approximately $50 \mu \mathrm{m}, 250 \mathrm{~nm}$ and $40 \mathrm{~nm}$, respectively. ${ }^{59}$ By comparing the absorption lengths to the $\mathrm{CB}-\mathrm{Cu}_{2} \mathrm{O}$ and $\mathrm{RD}$ $\mathrm{Cu}_{2} \mathrm{O}$ particle size (i.e. approx. $500 \mathrm{~nm}$ ), the absorption ranges for excitation at 1.8, 2.0, 2.5 and $2.7 \mathrm{eV}$ therefore, corresponding to homogeneous absorption by defects, homogeneous absorption through the whole particle, absorption only in the $\mathrm{Cu}_{2} \mathrm{O}$ crystallites closest to the reference electrode (top crystallites) and absorption within a very thin near surface layer, respectively.

Fig. 7c summarizes the dependencies of $A_{1}$ and $A_{2}$ as a function of the absorption range for $\mathrm{CB}-\mathrm{Cu}_{2} \mathrm{O}$ and $\mathrm{RD}-\mathrm{Cu}_{2} \mathrm{O}$. For CB- $\mathrm{Cu}_{2} \mathrm{O}, A_{1}$ increases from $10 \mu \mathrm{V}(1.8 \mathrm{eV})$ to $140 \mu \mathrm{V}(2.7 \mathrm{eV})$, while $A_{2}$ initially increases from $30 \mu \mathrm{V}(1.8 \mathrm{eV})$ to $80 \mu \mathrm{V}$ at $2.0 \mathrm{eV}$ and saturation at $100 \mu \mathrm{V}$ at higher photon energies. Given that the amplitude of the "fast" process $\left(A_{1}\right)$ increases continuously with decreasing absorption length, while the amplitude of the "slow" process $\left(A_{2}\right)$ saturates at higher photon energies, the "fast" processes are likely related to the absorption within a thin near-surface layer while the "slow" processes correspond to the absorption over the whole $\mathrm{Cu}_{2} \mathrm{O}$ particles. For $\mathrm{RD}-\mathrm{Cu}_{2} \mathrm{O}$, $A_{1}$ and $A_{2}$ increase from 1.5 and $2.3 \mu \mathrm{V}(1.8 \mathrm{eV})$, to 4.5 and $3.5 \mu \mathrm{V}$ $(2.0 \mathrm{eV})$, then decreases to 2.5 and $3.0 \mu \mathrm{V}(2.5 \mathrm{eV})$ and finally to 2.0 and $2.2 \mu \mathrm{V}(2.7 \mathrm{eV})$. The variations are considered insignificant, given the facts that, first, the modulated SPV signals of $\mathrm{RD}-\mathrm{Cu}_{2} \mathrm{O}$ are very low and, second, the signals even decrease with decreasing absorption length, despite the improved photocatalytic performance. Interestingly, the constant $\tau_{1}$ and $\tau_{2}$ used to fit the SPV amplitudes of $\mathrm{CB}-\mathrm{Cu}_{2} \mathrm{O}$ across various frequencies 

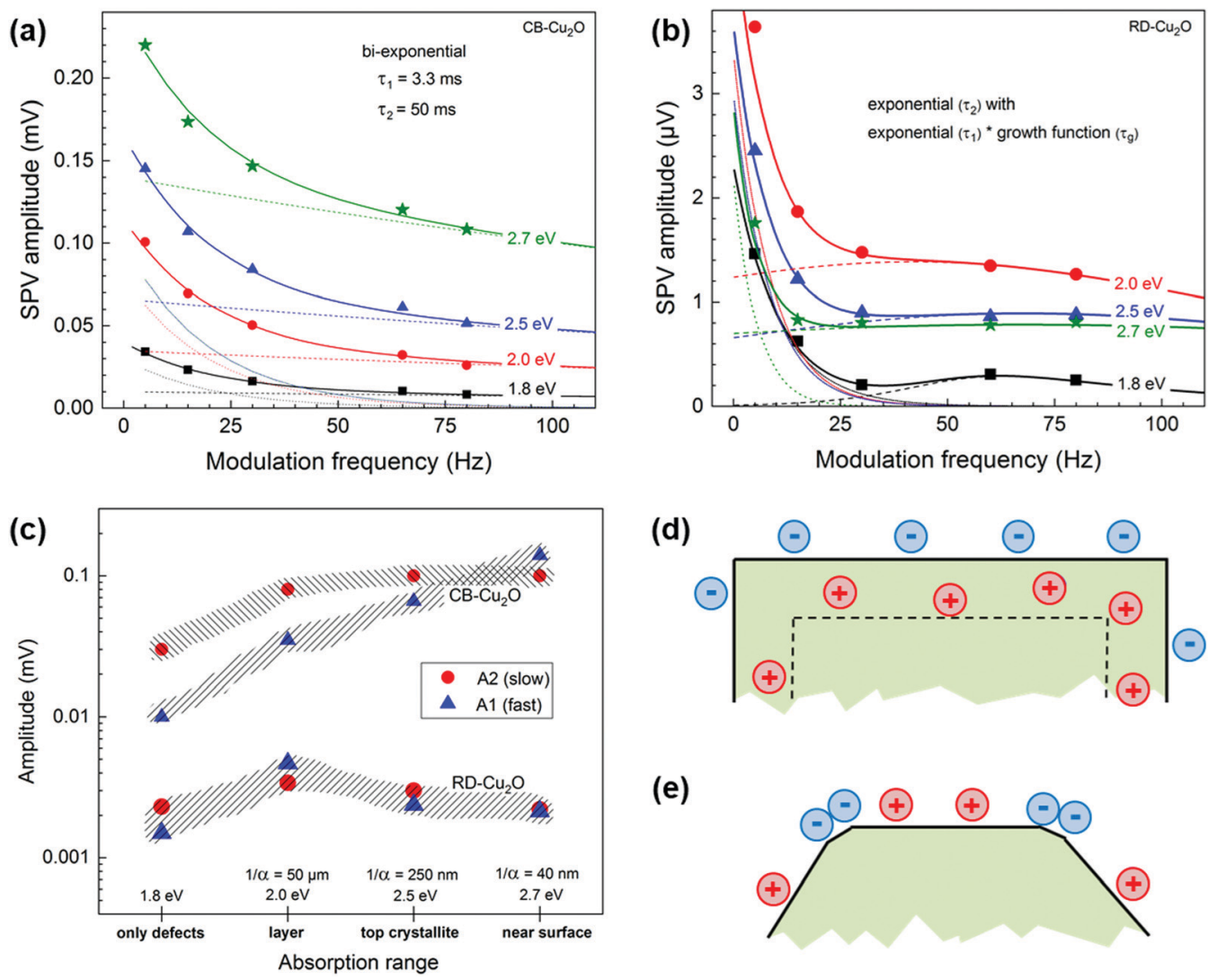

(d)

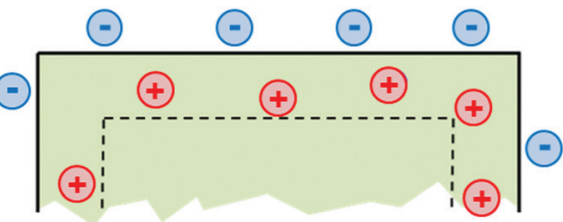

(e)

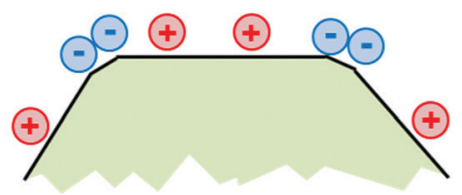

Fig. 7 Dependencies of the SPV amplitude on modulation frequency measured at photon energies of 1.8, 2.0, 2.5 and $2.7 \mathrm{eV}$ (squares, circles, triangles and stars, respectively) of (a) $\mathrm{CB}-\mathrm{Cu}_{2} \mathrm{O}$ (solid line is the bi-exponential fits, while dotted and dashed lines show the two separate exponentials, respectively) and (b) $\mathrm{RD}-\mathrm{Cu}_{2} \mathrm{O}$ (the solid line shows an exponential fits with a peak indicating the product of an exponential with a logistic growth function, while the thin dotted and dashed lines show the corresponding separate exponentials and peaks, respectively). (c) Summary of the dependencies of the amplitudes of the "fast" (triangles) and "slow" (circles) processes on the (qualitative) absorption range for $\mathrm{CB}-\mathrm{Cu}_{2} \mathrm{O}$ (upper part) and $\mathrm{RD}-\mathrm{Cu}_{2} \mathrm{O}$ (lower part). Schematic distribution of positive surface charge and negative charge (d) in a surface space charge region (depletion layer) within a doped homogeneous $\mathrm{CB}-\mathrm{Cu}_{2} \mathrm{O}$ and (e) modulated by different facets of $\mathrm{RD}-\mathrm{Cu}_{2} \mathrm{O}$.

(refer to ESI $\dagger$ for more details) has shown that $\tau_{1}$ and $\tau_{2}$ are independent of the photon energies and absorption lengths, signifying homogeneous charge separation within $\mathrm{CB}_{-} \mathrm{Cu}_{2} \mathrm{O}$. On the other hand, the time constants for $\mathrm{RD}-\mathrm{Cu}_{2} \mathrm{O}$ (particularly, the "fast" time constant) decrease with increasing photon energies, demonstrating that charge separation is not homogeneous in $\mathrm{RD}-\mathrm{Cu}_{2} \mathrm{O}$.

Modulated SPV signals correspond to the charge separation length projected to the normal reference electrode. In $\mathrm{CB}-\mathrm{Cu}_{2} \mathrm{O}$, the "fast" and "slow" processes are independent of the absorption range, indicating that there is one common driving force of charge separation. This common driving force is related to the built-in electrical field perpendicular to the surfaces of the facets. Given that $\mathrm{CB}-\mathrm{Cu}_{2} \mathrm{O}$ is a p-type doped semiconductor with moderate densities of equilibrium charge carriers, the width of the surface space charge region is of the order of $100 \mathrm{~nm}$, which is significantly shorter than the half extension of one $\mathrm{CB}-\mathrm{Cu}_{2} \mathrm{O}$ particle. Therefore, a homogeneously distributed opposite built-in electrical field perpendicular to the facets of $\mathrm{CB}-\mathrm{Cu}_{2} \mathrm{O}$ is the driving force for charge separation, facilitating separation of majority charge carrier (holes) inwards, as illustrated in Fig. 7d. In $\mathrm{RD}-\mathrm{Cu}_{2} \mathrm{O}$, the phenomenon is completely different than that in $\mathrm{CB}-\mathrm{Cu}_{2} \mathrm{O}$ since built-in electrical fields can be neglected, due to the lower density of equilibrium charge carriers (aligned with our dark microwave conductivity measurement results). ${ }^{59}$ The enhanced photocatalytic activity in $\mathrm{RD}-\mathrm{Cu}_{2} \mathrm{O}$ is attributed to the effective driving force for local charge separation, such as charge separation towards different directions. Although $\mathrm{RD}-\mathrm{Cu}_{2} \mathrm{O}$ is dominantly enclosed by $\{110\}$ facets, the facet corners are not sharp and small facets (i.e. $\{100\}$ facets) can be observed. The existence of secondary facets within $\mathrm{RD}-\mathrm{Cu}_{2} \mathrm{O}$ presents an additional driving force for the charge to be separated effectively towards different exposed facets (photogenerated electrons to $\{100\}$ and holes to $\{110\}$ ), as delineated by Li et al. ${ }^{62}$ Selective photodeposition of Ag (Fig. S7, ESI $\dagger$ ) was performed to further confirm the spatial separation of charges within $\mathrm{RD}-\mathrm{Cu}_{2} \mathrm{O}$. $\mathrm{Ag}$ nanoparticles were randomly deposited on $\mathrm{CB}-\mathrm{Cu}_{2} \mathrm{O}$ (Fig. S7a, ESI $\dagger$ ) and selectively deposited on the corners of $\mathrm{RD}-\mathrm{Cu}_{2} \mathrm{O}$, as illustrated in Fig. S7b (ESI $\dagger$ ). This signifies that the photogenerated electrons preferentially migrated to the corners of $\mathrm{RD}-\mathrm{Cu}_{2} \mathrm{O}$ (i.e. $\{100\}$ facets), in accordance with the SPV results. As a result, the modulated 
charge separation across the surface of $\mathrm{RD}-\mathrm{Cu}_{2} \mathrm{O}$ is another reason for its enhanced photocatalytic performances.

In short, TRMC shows the significant improvement of effective carrier mobility and lifetime of $\mathrm{RD}-\mathrm{Cu}_{2} \mathrm{O}$, while $\mathrm{PL}$ and SPV also demonstrate its enhanced local charge separation efficiency. These results have consistently shown the carrier dynamics of $\mathrm{RD}-\mathrm{Cu}_{2} \mathrm{O}$ to be superior, which is the reason behind the enhanced photoactivity in PC and PEC systems. Note that, one may be tempted to conclude that the differences in the surface atomic and electronic structure (the typical facetdependent properties) are the dominant factors affecting the overall performance, since several studies showed that differences in the surface electronic structure and band bending greatly affect the performance of the photocatalyst. ${ }^{27-29,59}$ How- $^{-}$ ever, the collative results from this study clearly show that the structural defect densities and existence or secondary facet/ facet boundaries also play vital roles in determining the carrier dynamic of a semiconductor, and the photoreactivity of a photocatalyst is highly dependent on its intrinsic charge dynamics. In addition, the higher trapping density in CB$\mathrm{Cu}_{2} \mathrm{O}$ (due to the higher defect concentration) that enhances its conductivity and intensifies the SPV signals does not assure its good photocatalytic ability due to its inferior charge mobility and carrier separation efficiency. $\mathrm{CB}-\mathrm{Cu}_{2} \mathrm{O}$ with a homogeneous depletion layer at the surface prompts the photo-generated majority charge carriers (holes) to separate towards the center of the crystallite. Those charge carriers induce an electric field in the opposite direction, which increases the recombination rate during photocatalysis, supported by our PL results. In contrast, $\mathrm{RD}-\mathrm{Cu}_{2} \mathrm{O}$ with modulated charges in surface states enables photogenerated minority and majority charge carriers to separate towards different regions on the surface, where these photogenerated charges could participate in photocatalytic reactions.

\section{Conclusion}

Carrier dynamics within a faceted semiconductor are demonstrated to govern the photoactivity of $\mathrm{PC}_{2}$ generation and PEC

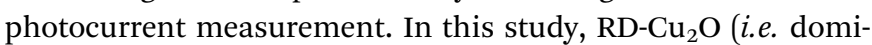
nant $\{110\}$ exposed facets) is shown to have better performances when compared to $\mathrm{CB}-\mathrm{Cu}_{2} \mathrm{O}$ with all $\{100\}$ exposed facets, attributed to the higher carrier mobility determined from the contactless TRMC measurement and better charge separation efficiency demonstrated by PL and SPV measurements. Although the surface atomic arrangement and the surface electronic band structure are commonly identified as the main factors that boost the photocatalytic performance of faceted $\mathrm{Cu}_{2} \mathrm{O}$, the inevitable evolution of defects during the synthesis and the presence of secondary facets are shown to affect the carrier dynamics of the samples. The higher defect concentrations formed within $\mathrm{CB}-\mathrm{Cu}_{2} \mathrm{O}$ increases its conductivity and carrier density. However, our results show that the higher defect density presents a detrimental effect on carrier mobility and separation, thus hinders the photoactivity of
$\mathrm{CB}-\mathrm{Cu}_{2} \mathrm{O}$. On the other hand, the superior carrier mobility, lifetime and diffusion length of the $\mathrm{RD}-\mathrm{Cu}_{2} \mathrm{O}$ sample are the dominant factors that enhance the performance in PC and PEC systems. Moreover, despite the stronger SPV signals of CB$\mathrm{Cu}_{2} \mathrm{O}$, the homogeneous depletion layer induces an opposite electric field on $\mathrm{CB}-\mathrm{Cu}_{2} \mathrm{O}$ and increases the charge recombination rate, while $\mathrm{RD}-\mathrm{Cu}_{2} \mathrm{O}$ with the presence of secondary facets allows efficiency charge separation towards different directions of the surfaces. In this work, all the possible facet-dependent properties involved in crystal facet engineering were carefully interpreted. Apart from surface absorption abilities and surface energies, these findings demonstrate that surface defect density (formed during the fabrication of faceted $\mathrm{Cu}_{2} \mathrm{O}$ ) and exposure of more than one facets are important factors that influence the photoactivity and should not be neglected.

\section{Experimental section}

\section{Material preparation}

A facile solution-phase method adapted from Liang et $a .^{1}{ }^{1}$ was used to fabricate cuprous oxide in this work. Initially, $80 \mathrm{~mL}$ of $0.05 \mathrm{M} \mathrm{CuSO}_{4} \cdot 5 \mathrm{H}_{2} \mathrm{O}$ (>99\%, UNIVAR) was mixed with $40 \mathrm{~mL}$ of ethanol (100\% unsaturated, chem-supply) followed by heating to $80{ }^{\circ} \mathrm{C}$ under constant stirring. $20 \mathrm{~mL}$ of $0.8 \mathrm{M}$ aqueous sodium hydroxide $(\mathrm{NaOH},>98 \%$, chem-supply) solution was then added and the suspension was held for another $5 \mathrm{~min}$ before the addition of $60 \mathrm{~mL}$-glucose $(6.42 \mathrm{~g}$, anhydrous, chem-supply) solution. Cubic $\mathrm{Cu}_{2} \mathrm{O}$ powder was then washed alternately with Milli-Q water and ethanol before drying in a vacuum desiccator. For rhombic dodecahedral $\mathrm{Cu}_{2} \mathrm{O}$, the procedure was repeated with the addition of $12 \mathrm{~mL}$ oleic acid (analytical standard, Sigma Aldrich) and the suspension was maintained at a temperature of $100{ }^{\circ} \mathrm{C}$.

\section{Material characterizations}

The morphologies and structures of the samples were examined by field-emission scanning electron microscopy (FE-SEM, FEI Nova NanoSEM 450). Crystallinity was investigated using Xray diffraction (XRD, X'pert MPD with $\mathrm{Cu} \mathrm{K} \alpha$ radiation at $45 \mathrm{kV}$ and $40 \mathrm{~mA}$ ). UV-Vis absorbance spectra were converted from diffuse reflectance spectra obtained on a Shimadzu UV 3600 spectrophotometer with $\mathrm{BaSO}_{4}$ as reference using the KubelkaMunk transformation. The Brunauer-Emmett-Teller (BET) surface area of $\mathrm{Cu}_{2} \mathrm{O}$ was assessed using a Micromeritics Tristar 3030 Analyser at $77 \mathrm{~K}$. Before the measurement, the samples were pre-treated at $150{ }^{\circ} \mathrm{C}$ for three hours in a Micrometric VacPrep unit.

The surface composition and valence band spectra of the samples were analysed via X-ray photoelectron spectroscopy (XPS, Thermo ESCALAB250Xi) probed with monochromatic Al $\mathrm{K} \alpha$ radiation $\left(h_{\mathrm{v}}=1486.68 \mathrm{eV}\right)$ in a vacuum chamber. The $\mathrm{C} 1 \mathrm{~s}$ peak at $284.4 \mathrm{eV}$ was used to calibrate the binding energy before spectra deconvolution. Electron paramagnetic resonance (EPR) measurements were carried out on Bruker EMX-plus operating at a $9.41 \mathrm{GHz}$ frequency (X-band) with a microwave power of 
$2 \mathrm{~mW}$ at a temperature of $125 \mathrm{~K}$. Photoluminescence spectra were obtained using Horiba Fluoromax-4 spectrofluorometer with an excitation wavelength of $525 \mathrm{~nm}$.

\section{Photocatalytic hydrogen $\left(\mathrm{H}_{2}\right)$ generation}

Photocatalytic $\mathrm{H}_{2}$ evolution was performed with top illumination through the quartz window of an enclosed Y-reactor. $50 \mathrm{mg}$ of samples were dispersed in $200 \mathrm{~mL}$ of $0.5 \mathrm{M} \mathrm{Na}_{2} \mathrm{SO}_{3}$ solution. Prior to illumination, argon gas (100\%, Coregas) was used to deaerate the suspension for $30 \mathrm{~min}$ to remove all the dissolved gases. A $300 \mathrm{~W}$ xenon lamp (CERMAX) with an intensity of $385 \mathrm{~mW} \mathrm{~cm}^{-2}$ was employed as the light source (Light spectrum provided in Fig. S8, ESI $\dagger$ ). $\mathrm{H}_{2}$ evolved during the illumination was monitored by a gas chromatograph (Shimadzu GC-8A, HayeSep DB column) at $30 \mathrm{~min}$ intervals. After the reaction, the post-reaction catalyst was retrieved by centrifugation (10000 rpm for $15 \mathrm{~min}$ ) for further characterizations. The solid sample collected was further dispersed in MilliQ water and centrifuged (repeated for three times) to remove any salt $\left(\mathrm{Na}_{2} \mathrm{SO}_{3}\right.$ or $\mathrm{Na}_{2} \mathrm{SO}_{4}$, oxidized from $\mathrm{Na}_{2} \mathrm{SO}_{3}$ ) residue deposited on the surface of the catalyst during the reaction. Finally, the solid catalyst was dried and kept in a vacuum desiccator before characterizations. Control experiments were performed using the same enclosed Y-reactor containing $50 \mathrm{mg}$ of photocatalyst dispersed in $200 \mathrm{~mL}$ of $0.5 \mathrm{M}$ $\mathrm{Na}_{2} \mathrm{SO}_{3}$ solution without light irradiation.

\section{Photoelectrochemical (PEC) measurement}

Drop casted samples on FTO substrates $\left(2 \mathrm{mg} \mathrm{cm}^{-2}\right)$ were used for PEC measurements. To obtain a $2 \mathrm{mg} \mathrm{cm}^{-2} \mathrm{Cu}_{2} \mathrm{O}$ thin film, bare FTO was cleaned thoroughly in ethanol, acetone and milliQ water. Next, $6 \mathrm{mg}$ of $\mathrm{Cu}_{2} \mathrm{O}$ were dispersed in $6 \mathrm{~mL}$ of ethanol via sonication for at least $15 \mathrm{~min}$. $0.1 \mathrm{~mL}$ of the suspension containing $\mathrm{Cu}_{2} \mathrm{O}$ was then dropped on a $3 \mathrm{~cm}^{2}$ cleaned FTO at room temperature. This step was repeated at a 15 min interval until all the suspension was dropcasted. During the dropcasting process, it is crucial to ensure that the film is completely dried before the subsequent layer was deposited to avoid segregation of particles and create an evenly distributed $\mathrm{Cu}_{2} \mathrm{O}$ thin film. A three-electrode PEC system with a $\mathrm{Cu}_{2} \mathrm{O}$ working electrode, $\mathrm{Ag} / \mathrm{AgCl}$ reference electrode, $\mathrm{Pt}$ counter electrode immersed in $0.1 \mathrm{M} \mathrm{Na}_{2} \mathrm{SO}_{4}$ solution was employed to evaluate the PEC responses. Photocurrent densities were recorded as amperometry curves and on-set potentials were determined from linear sweep voltammetry curves using a potentiostat (Model PGSTAT302N, Autolab) under on-off irradiation by $300 \mathrm{~W}$ xenon lamp (CERMAX).

\section{Density functional theory (DFT) calculations}

Electronic structure calculations were performed using DFT as implemented in VASP. ${ }^{63,64}$ Core and valence electronics were described using the projector augmented wave (PAW) method and exchange-correlation parametrization according to the PBE functional. ${ }^{65}$ The wavefunctions were expanded in the planewave basis using an energy cutoff of $500 \mathrm{eV}$. Dispersion effects were corrected for using Grimme van der Waals parameters. ${ }^{66}$ Surfaces were constructed using symmetric slabs with $15-17$ atomic layers separated by $\sim 20 \AA$ of vacuum to reduce interaction along the periodic $z$-direction. To correctly account for electronic correlations, a GGA $+U_{\text {eff }}\left(U_{\text {eff }}=7 \mathrm{eV}\right)$ was used. A $U_{\text {eff }}$ value in the range of $5-8 \mathrm{eV}$ was shown to reproduce key electronic and geometric properties of $\mathrm{Cu}_{2} \mathrm{O} .{ }^{67-69}$ All atomic positions were allowed to relax until forces were less than $0.01 \AA \mathrm{eV}^{-1}$ and self-consistent field energies change by no more than $1 \times 10^{-5} \mathrm{eV}$. The adsorbate binding energies are calculated using eqn (5),

$$
E_{\mathrm{b}}\left(\mathrm{H}^{*}\right)=E_{\mathrm{tot}}\left(\mathrm{H}^{*}\right)-E_{\mathrm{tot}}(\text { surface })-1 / 2 E_{\mathrm{tot}}\left(\mathrm{H}_{2}\right)
$$

where $E_{\text {tot }}\left(\mathrm{H}^{*}\right), E_{\text {tot }}($ surface $)$ and $1 / 2 E_{\text {tot }}\left(\mathrm{H}_{2}\right)$ are the total energies of the $\mathrm{H}$ bound to the surface, the bare surface, and the energy of a $\mathrm{H}_{2}$ molecule. Similar relations are derived for $\mathrm{H}_{2}$ and $\mathrm{H}_{2} \mathrm{O}$ binding. Binding energies can be converted into Gibb's free energies by including zero-point (ZPE) and entropic terms (TS). In the case of hydrogen adsorption this equates to $0.24 \mathrm{eV}$ per $\mathrm{H}^{*}$.

\section{Time resolved microwave conductivity (TRMC) measurement}

For TRMC measurements, the films were prepared by drop casting the samples $\left(2 \mathrm{mg} \mathrm{cm}{ }^{-2}\right)$ on a $25 \mathrm{~mm} \times 12 \mathrm{~mm}$ quartz substrate at room temperature. The substrate was then mounted to a specially designed microwave cavity cell, and the cell was fitted into a setup consisting of a microwave source (X-band, 8.4-8.7 GHz), a Q-switched Nd:YAG laser $(\lambda=355$ or $532 \mathrm{~nm}$, i.e. frequency-tripled or -doubled) and a microwave detector as illustrated in other works. ${ }^{56,70}$ The resonant frequency of the cavity loaded with our $\mathrm{Cu}_{2} \mathrm{O}$ samples was found to be $8.51 \mathrm{GHz}$; this frequency was employed in all our measurement. The changes in reflected microwave power from the cavity upon $6.0 \mathrm{~ns}$ FWHM pulsed laser excitation, $\Delta P / P$, were monitored throughout the measurement. This value was then used to calculate the change in the conductance of the sample, $\Delta G$ according to eqn (6). The correlations between the measured changes in microwave power $(\Delta P / P)$, conductance $(\Delta G)$ and carrier mobility $(\mu)$ allow the TRMC signal to be expressed as a product of internal quantum efficiency $(\phi)$ and the sum of carrier mobility $\left(\sum \mu\right)$. Using this $\Delta G$ value, the product of the internal quantum efficiency $(\phi$, which is the number of excited mobile carriers normalized to the number of absorbed photons, typically taken as 1 for an inorganic semiconductor) and the sum of carrier mobility $\left(\sum \mu\right)$ can be computed following eqn (7). Here, for both wavelengths (355 and $532 \mathrm{~nm}$ ), pulsed laser intensities were adjusted using a neutral density filter, and the values were between $10^{10}$ and $10^{15}$ photons $\mathrm{cm}^{-2}$ pulse ${ }^{-1}$.

$$
\begin{gathered}
\frac{\Delta P}{P}(t)=-K \Delta G(t) \\
\phi \sum \mu=\frac{\Delta G}{I_{\mathrm{o}} \beta e F_{\mathrm{A}}}
\end{gathered}
$$

In eqn (6), $K$ is the sensitivity factor calculated from the dark resonance parameters of the cavity and dielectric constant of $\mathrm{Cu}_{2} \mathrm{O}$ (taken as 6.6). ${ }^{51,71} I_{\mathrm{O}}$ is the photon intensity per pulse, $\beta$ is 
the ratio of the cavity's dimensions, $e$ is the elementary charge $\left(1.602 \times 10^{-19} \mathrm{C}\right)$ and $F_{\mathrm{A}}$ is the fraction of light absorbed by the sample at the particular wavelength.

\section{Modulated surface photovoltage (SPV) spectroscopy measurement}

Modulated SPV spectroscopy measurements were performed in a fixed capacitor arrangement, as reported previously. ${ }^{72}$ The SPV signals were measured using high-impedance buffers (input impedance of $150 \mathrm{G} \Omega$ ). A halogen lamp with a quartz prism monochromator (SPM2, Zeiss) was used for modulated illumination. A mechanical chopper was placed in front of the entrance slit of the monochromators. The modulated in-phase and quadrature (i.e. $90^{\circ}$ out-of-phase) signals were detected with a dual-phase DSP lock-in amplifier (EG\&G 7260). The phase was calibrated with a Si photodiode. In modulated SPV spectroscopy, signals are measured in accordance to the phase of the modulation. The in-phase signals follow the modulation and give information about the "fast" response in relation to the modulation period. In contrast, signals phase-shifted by $90^{\circ}$ give information about the "slow" response. The SPV amplitude $(R)$ is defined as the square root of the sum of the squared in-phase and phase-shifted by $90^{\circ}$ signals (refer to reported literature). ${ }^{34}$ Modulated SPV spectra were measured at different modulation frequency $\left(f_{\text {mod }}\right)$ in order to distinguish dominating mechanisms of charge separation and relaxation.

\section{Photodeposition of $\mathrm{Ag}$ nanoparticles}

Photodeposition of $\mathrm{Ag}$ on $\mathrm{CB}-\mathrm{Cu}_{2} \mathrm{O}$ and $\mathrm{RD}-\mathrm{Cu}_{2} \mathrm{O}$ were performed in the same reactor system as photocatalytic $\mathrm{H}_{2}$ generation (top illumination through quartz window of an enclosed Y-reactor). $50 \mathrm{mg}$ of samples were dispersed in $200 \mathrm{~mL}$ of $0.25 \mathrm{mM}$ aqueous $\mathrm{AgNO}_{3}$ solution. The system was purged with $\mathrm{Ar}$ gas for at least $30 \mathrm{~min}$ to remove $\mathrm{O}_{2}$ that could potentially compete with $\mathrm{Ag}$ deposition reaction. The suspension was illuminated for an hour before retrieving the products (Ag-deposited $\mathrm{Cu}_{2} \mathrm{O}$ particles) via centrifugation.

\section{Conflicts of interest}

There are no conflicts to declare.

\section{Acknowledgements}

This work was financially supported by the Australian Research Council Discovery Project (DP180102540) and Hong Kong General Research Fund (GRF11305419 and GRF11306920). The authors appreciate the facility and technical support provided by the UNSW Mark Wainwright Analytical Centre. The authors acknowledge Dr Dennis Friedrich for his inputs during timeresolved microwave conductivity measurements in HelmholtzZentrum Berlin.

\section{References}

1 E. S. Jang, J. H. Won, S. J. Hwang and J. H. Choy, Adv. Mater., 2006, 18, 3309-3312.

2 R. Li, F. Zhang, D. Wang, J. Yang, M. Li, J. Zhu, X. Zhou, H. Han and C. Li, Nat. Commun., 2013, 4, 1432.

3 C. Zhang and Y. Zhu, Chem. Mater., 2005, 17, 3537-3545.

4 J. Pan, G. Liu, G. Q. M. Lu and H. M. Cheng, Angew. Chem., Int. Ed., 2011, 50, 2133-2137.

5 X. Liang, L. Gao, S. Yang and J. Sun, Adv. Mater., 2009, 21, 2068-2071.

6 X. Peng, L. Manna, W. Yang, J. Wickham, E. Scher, A. Kadavanich and A. P. Alivisatos, Nature, 2000, 404, 59-61.

7 Y. Sun and Y. Xia, Science, 2002, 298, 2176-2179.

8 T. Ohno, K. Sarukawa and M. Matsumura, New J. Chem., 2002, 26, 1167-1170.

9 H. L. Tan, X. Wen, R. Amal and Y. H. Ng, J. Phys. Chem. Lett., 2016, 7, 1400-1405.

10 L. Zhang, W. Wang, S. Sun, D. Jiang and E. Gao, Appl. Catal., $B, 2015,162,470-474$.

11 X. Wu, Y. H. Ng, L. Wang, Y. Du, S. X. Dou, R. Amal and J. Scott, J. Mater. Chem. A, 2017, 5, 8117-8124.

12 H. Wu, Z. Zheng, C. Y. Toe, X. Wen, J. N. Hart, R. Amal and Y. H. Ng, J. Mater. Chem. A, 2020, 8, 5638-5646.

13 L. Chen, Y. Zhang, P. Zhu, F. Zhou, W. Zeng, D. D. Lu, R. Sun and C. Wong, Sci. Rep., 2015, 5, 9672.

14 C. H. B. Ng and W. Y. Fan, J. Phys. Chem. B, 2006, 110, 20801-20807.

15 J. Xu and D. Xue, Acta Mater., 2007, 55, 2397-2406.

16 L. Gou and C. J. Murphy, Nano Lett., 2003, 3, 231-234.

17 Y. Zhao, W. Wang, Y. Li, Y. Zhang, Z. Yan and Z. Huo, Nanoscale, 2014, 6, 195-198.

18 C.-H. Kuo and M. H. Huang, J. Am. Chem. Soc., 2008, 130, 12815-12820.

19 X. Lu, J. N. Hart, Y. Yao, C. Y. Toe, J. Scott and Y. H. Ng, Mater. Today Energy, 2020, 16, 100422.

20 Y. Zhang, B. Deng, T. Zhang, D. Gao and A.-W. Xu, J. Phys. Chem. C, 2010, 114, 5073-5079.

21 C. Y. Toe, Z. Zheng, H. Wu, J. Scott, R. Amal and Y. H. Ng, J. Phys. Chem. C, 2018, 122, 14072-14081.

22 H. Bao, W. Zhang, D. Shang, Q. Hua, Y. Ma, Z. Jiang, J. Yang and W. Huang, J. Phys. Chem. C, 2010, 114, 6676-6680.

23 D.-F. Zhang, H. Zhang, L. Guo, K. Zheng, X.-D. Han and Z. Zhang, J. Mater. Chem., 2009, 19, 5220-5225.

24 C. Y. Toe, J. Scott, R. Amal and Y. H. Ng, J. Photochem. Photobiol., C, 2019, 40, 191-211.

25 W.-C. Huang, L.-M. Lyu, Y.-C. Yang and M. H. Huang, J. Am. Chem. Soc., 2012, 134, 1261-1267.

26 Y. Kwon, A. Soon, H. Han and H. Lee, J. Mater. Chem. A, 2015, 3, 156-162.

27 G. Z. Yuan, C. F. Hsia, Z. W. Lin, C. Chiang, Y. W. Chiang and M. H. Huang, Chem. - Eur. J., 2016, 22, 12548-12556.

28 Z. Zheng, B. Huang, Z. Wang, M. Guo, X. Qin, X. Zhang, P. Wang and Y. Dai, J. Phys. Chem. C, 2009, 113, 14448-14453.

29 C.-Y. Chu and M. H. Huang, J. Mater. Chem. A, 2017, 5, 15116-15123. 
30 S. Nishioka, J. Hyodo, J. J. M. Vequizo, S. Yamashita, H. Kumagai, K. Kimoto, A. Yamakata, Y. Yamazaki and K. Maeda, ACS Catal., 2018, 8, 7190-7200.

31 J. Zhu, S. Pang, T. Dittrich, Y. Gao, W. Nie, J. Cui, R. Chen, H. An, F. Fan and C. Li, Nano Lett., 2017, 17, 6735-6741.

32 R. Chen, S. Pang, H. An, T. Dittrich, F. Fan and C. Li, Nano Lett., 2019, 19, 426-432.

33 H. L. Tan, F. F. Abdi and Y. H. Ng, Chem. Soc. Rev., 2019, 48, 1255-1271.

34 D. Thomas and F. Steffen, Surface photovoltage analysis of photoactive materials, World Scientific, 2020.

35 W. Ching, Y.-N. Xu and K. Wong, Phys. Rev. B, 1989, 40, 7684-7695.

36 H. Wu, H. L. Tan, C. Y. Toe, J. Scott, L. Wang, R. Amal and Y. H. Ng, Adv. Mater., 2020, 32, 1904717.

37 X. Wu, C. Y. Toe, C. Su, Y. H. Ng, R. Amal and J. Scott, J. Mater. Chem. A, 2020, 8, 15302-15318.

38 A. Kudo and Y. Miseki, Chem. Soc. Rev., 2009, 38, 253-278.

39 H. L. Tan, R. Amal and Y. H. Ng, J. Mater. Chem. A, 2017, 5, 16498-16521.

40 G. Liu, C. Y. Jimmy, G. Q. M. Lu and H.-M. Cheng, Chem. Commun., 2011, 47, 6763-6783.

41 C. Y. Toe, Z. Zheng, H. Wu, J. Scott, R. Amal and Y. H. Ng, Angew. Chem., Int. Ed., 2018, 57, 13613-13617.

42 A. Soon, M. Todorova, B. Delley and C. Stampfl, Phys. Rev. B, 2007, 75, 125420.

43 A. Hagfeldt, S.-E. Lindquist and M. Grätzel, Sol. Energy Mater. Sol. Cells, 1994, 32, 245-257.

44 D. Scaife, Sol. Energy, 1980, 25, 41-54.

45 S. Lee, C.-W. Liang and L. W. Martin, ACS Nano, 2011, 5, 3736-3743.

46 Z. Zhang and J. T. Yates Jr, Chem. Rev., 2012, 112, 5520-5551.

47 W. Z. Wang, G. Wang, X. S. Wang, Y. Zhan, Y. Liu and C. L. Zheng, Adv. Mater., 2002, 14, 67-69.

48 H. L. Tan, A. Suyanto, A. T. D. Denko, W. H. Saputera, R. Amal, F. E. Osterloh and Y. H. Ng, Part. Part. Syst. Charact., 2017, 34, 1600290.

49 S. Chawla, N. Sankarraman and J. Payer, J. Electron Spectrosc. Relat. Phenom., 1992, 61, 1-18.

50 M. Swadźba-Kwaśny, L. Chancelier, S. Ng, H. G. Manyar, C. Hardacre and P. Nockemann, Dalton Trans., 2012, 41, 219-227.

51 D. Tahir and S. Tougaard, J. Phys.: Condens. Matter, 2012, 24, 175002 .
52 M. Łabanowska, E. Bidzińska, K. Dyrek, T. Fortuna, S. Pietrzyk, J. Rożnowski and R. P. Socha, Starch - Stärke, 2008, 60, 134-145.

53 F. F. Abdi, T. J. Savenije, M. M. May, B. Dam and R. van de Krol, J. Phys. Chem. Lett., 2013, 4, 2752-2757.

54 M. de Respinis, M. Fravventura, F. F. Abdi, H. Schreuders, T. J. Savenije, W. A. Smith, B. Dam and R. van de Krol, Chem. Mater., 2015, 27, 7091-7099.

55 T. J. Savenije, A. Huijser, M. J. Vermeulen and R. Katoh, Chem. Phys. Lett., 2008, 461, 93-96.

56 J. E. Kroeze, T. J. Savenije and J. M. Warman, J. Am. Chem. Soc., 2004, 126, 7608-7618.

57 F. Plascencia-Hernández, A. L. Luna, C. Colbeau-Justin, P. Santiago, M. Garcia-Rocha, G. Valverde-Aguilar and M. A. Valenzuela, J. Saudi Chem. Soc., 2019, 23, 1016-1023.

58 J. W. Jang, D. Friedrich, S. Müller, M. Lamers, H. Hempel, S. Lardhi, Z. Cao, M. Harb, L. Cavallo and R. Heller, Adv. Energy Mater., 2017, 7, 1701536.

59 C.-S. Tan, S.-C. Hsu, W.-H. Ke, L.-J. Chen and M. H. Huang, Nano Lett., 2015, 15, 2155-2160.

60 J. Liqiang, Q. Yichun, W. Baiqi, L. Shudan, J. Baojiang, Y. Libin, F. Wei, F. Honggang and S. Jiazhong, Sol. Energy Mater. Sol. Cells, 2006, 90, 1773-1787.

61 L. Kronik and Y. Shapira, Surf. Interface Anal., 2001, 31, 954-965.

62 R. Li, X. Tao, R. Chen, F. Fan and C. Li, Chem. - Eur. J., 2015, 21, 14337-14341.

63 G. Kresse and J. Furthmüller, Phys. Rev. B, 1996, 54, 11169.

64 G. Kresse and J. Furthmüller, Comput. Mater. Sci., 1996, 6, 15-50.

65 P. E. Blöchl, Phys. Rev. B, 1994, 50, 17953.

66 S. Grimme, J. Comput. Chem., 2006, 27, 1787-1799.

67 M. Nolan and S. D. Elliott, Phys. Chem. Chem. Phys., 2006, 8, 5350-5358.

68 L. I. Bendavid and E. A. Carter, J. Phys. Chem. C, 2013, 117, 26048-26059.

69 A. Živković, A. Roldan and N. H. De Leeuw, Phys. Rev. B, 2019, 99, 035154.

70 J. T. Carneiro, T. J. Savenije and G. Mul, Phys. Chem. Chem. Phys., 2009, 11, 2708-2714.

71 F. Weichman, Can. J. Phys., 1973, 51, 680-685.

72 V. Duzhko, V. Y. Timoshenko, F. Koch and T. Dittrich, Phys. Rev. B, 2001, 64, 075204. 